E.L.U.A.., 13, 1999, págs.: 155-192.

\title{
PAPELES SEMÁNTICOS, PREPOSICIONES Y OBJETOS PREPOSICIONALES ${ }^{1}$
}

\author{
$\mathrm{M}^{\mathrm{a}}$ ANTONIA MARTÍNEZ LINARES \\ (Universidad de Alicante)
}

In this work, I have examined some interpretations of the relational meaning of several oblique arguments. I have pointed out some discrepancies in the interpretations of these complements. Finally, I have commented on some problemational questions abount semantic roles and I have remarked that these questions could be involved in the mentioned discrepancies.

\section{Introducción}

En sus conclusiones sobre los caracteres que se han ido utilizando para definir la noción de 'suplemento', desde que Alarcos (1968) introdujo en los estudios gramaticales del español este concepto, Gutiérrez Ordóñez afirmaba que «sería necesario un estudio de las distintas funciones semánticas realizadas por los suplementos y su compatibilidad con las que manifiestan los aditamentos» (1997: 193). A ello añadía que, probablemente, si «introducimos parámetros de contenido, las diferencias entre suplemento y aditamento aparezcan aún más difusas» (ibid.).

\footnotetext{
'Utilizo el término 'objeto preposicional' para referirme a los complementos - no 'directos' o 'indirectos' - introducidos por una preposición que forman parte de la valencia verbal. No obstante, la elección del término no obedece a ninguna razón especial y a lo largo de mi exposición utilizo igualmente otros términos, como 'suplemento' o 'complemento preposicional', que se han venido empleando en los estudios gramaticales del español para aludir a este tipo de complementación verbal.

Este trabajo ha sido financiado en parte gracias a una ayuda concedida por la Subdirección GeneraI de Formación y Promoción del Conocimiento, del Ministerio de Educación y Cultura, para el Proyecto de investigación PB95-0692, del que forma parte.
} 
Sin prejuzgar cuál ha de ser el lugar que realmente deben ocupar los papeles semánticos (o participantes, o temáticos) en la gramática, la sugerencia de Gùtiérrez Ordóñez parece muy oportuna dada la relevancia que han llegado a tener los papeles en el panorama actual de las corrientes sintácticas.

Aunque es uno de los aspectos que más adelante iré desarrollando, no conviene olvidar que ni existe un concepto uniforme de papel semántico o temático, ni tampoco hay en absoluto acuerdo acerca de su estatus. Por ello las generalizaciones que hacen referencia a los papeles semánticos tomando en consideración marcos teóricos distintos tienen un valor muy limitado. Pero, no obstante, parece claro que las nociones designadas con términos tales como 'agente', 'tema', 'paciente', 'meta', 'locación', 'origen', 'beneficiario', etc., así como sus vínculos y sus conexiones con las relaciones gramaticales, estructuradas a través de jerarquías de papeles semánticos, constituyen actualmente un aspecto insoslayable en el tratamiento de los fenómenos morfosintácticos.

Son numerosas las teorías que apelan a este tipo de nociones como componentes centrales de las representaciones léxicas de los verbos y, en definitiva, de la información, relevante para la gramática, que debe quedar reflejada en el lexicón o diccionario. En algunas de las corrientes lingüísticas que han gozado de mayor influencia y difusión en el ámbito de la gramática, como es el caso de los desarrollos más recientes de la gramática generativa chomskyana, se han erigido en nociones clave, dado que se vinculan directamente a las realizaciones sintácticas y se han postulado, asimismo, como base para la explicación de numerosos procesos morfológicos y sintácticos. Y, en cualquier caso, como indica Van Valin (1996: 98), «Almost every syntactic theory makes use of these notions in some way either overtly or covertly».

Pero si bien en los estudios gramaticales del español han sido numerosos los trabajos interesados en matizar los criterios objetivos ${ }^{2}$ utilizados para delimitar la «función» ${ }^{3}$ suplemento, complemento regido u objeto preposicional, la afirmación de Gutiérrez Ordóñez ${ }^{4}$ sobre la necesidad de estudiar las distintas funciones

\footnotetext{
2 Me refiero a los criterios - supresión, adición libre, reaparición junto a hacerlo—utilizados para justificar el carácter más o menos valencial del complemento; la posibilidad de conmutar la preposición que introduce el complemento por otra de significado similar; la compatibilidad o incompatibilidad de objeto directo y suplemento; la viabilidad de la conmutación por adverbio, etc.

3 En los estudios gramaticales del español se suele hablar del suplemento, así como del complemento adverbial, como funciones sintácticas, diferenciadas tanto del objeto directo y del indirecto como del complemento circunstancial. Sin embargo, sobre este punto no existe unanimidad, pues también se ha sugerido (García-Miguel, 1995; Vera Luján, 1994; González Calvo, 1994) que no parece haber criterios gramaticales que justifiquen una función suplemento distinta del complemento circunstancial.

Tambien Kailuweit (1993: 271) señalaba al referirse a los complementos preposicionales que «hay que continuar los análisis semánticos para tener un aparato interpretativo adecuado que permita no sólo solucionar casos sintácticamente ambiguos, sino también aclarar la relación entre el comportamiento sintáctico (nivel de expresión) y el significado gramatical (nivel de contenido). La teoría de los papeles
} 
semánticas realizadas por el suplemento parece apuntar a que, en lo que concierne a «parámetros de contenido», aún queda mucho por analizar, máxime si se tiene en cuenta la extensión ${ }^{5}$ que ha ido tomando la «clase» suplemento u objeto preposicional, tomando como base la presencia de la preposición y la nuclearidad o valencialidad $^{6}$ : incluye tanto suplementos «directos» (hablaban de politica, recurri a ellos), como «indirectos» (lo implicó en una estafa, lo acusaron de asesinato); complementos en los que la preposición mantiene un claro sentido espacial (residian en Vigo, se dirigió a su casa) y complementos introducidos por una preposición que o bien se considera «vacía» o, cuando menos, presenta un

temáticos (o casos) será útil para alcanzar esa meta». Si bien añadía más abajo que «esta teoría padece hasta ahora de un falso universalismo y debe ser ajustada a la estructuración que hace cada lengua de lo elocutivo»s.

5 Según indica Cuesta Martínez (1997: 57), «las notas definitorias de esta función sintáctica han sufrido una serie de vicisitudes — matizaciones, modificaciones, ampliaciones, entre ellas las del propio Alarcos- que han incrementado su importancia, pero también su complejidad. En la actualidad (...) no sólo un gran número de construcciones son susceptibles de analizarse como suplementarias sino que, además, se ha visto la necesidad de crear nuevas distinciones entre los adyacentes del área verbal».

${ }_{6}$ Me refiero a los dos rasgos más frecuentemente utilizados en la caracterización del suplemento u objeto preposicional, si bien la cuestión de la obligatoriedad de la preposición viene a enlazar con la pertinencia de la distinción suplemento-complemento adverbial. De ahí que ni siquiera acerca de la presencia obligatoria de la preposición exista unanimidad.

Para Cuesta Martínez, por ejemplo, que siguiendo a Rojo $(1985,1990)$, acepta «la conmutación (global) por adverbio» como «criterio válido para distinguir entre suplemento y complemento adverbial» (1997: 70), es «la nuclearidad del suplemento, junto con su carácter prepositivo - que excluye, por lo tanto, cualquier conmutabilidad por adverbio- y junto con su resto no átono en caso de consabido, la característica que nos permite definir en un plano teórico y con una generalidad que no incluya excepciones, la identidad del suplemento con respecto a los restantes adyacentes del sintagma verbal. Sería, por lo tanto, suplemento, todo sintagma preposicional nuclear, no conmutable por resto átono ni por adverbio sin preposición». Por tanto, según su opinión, en proceden de Francia (proceden de allí), habría suplemento, porque se mantiene la preposición. En cambio, en residen en Vigo (residen allí) no, porque hay sustitución global por un adverbio, incluida la preposición (1997: 61).

Gutiérrez Ordóñez (1997; 191-192), sin embargo, considera innecesaria la oposición entre suplemento y complemento adverbial. Sólo el criterio de la mayor o menor marginalidad, pero no el de la sustitución adverbial, puede ser pertinente para diferenciar las funciones suplemento y aditamento: «La existencia de suplementos sin preposición (residen alli, pon las cartas alli) obedece a un hecho formal: la proforma alli es incompatible con preposiciones que signifiquen «lugar en donde» (en, ante, bajo, sobre, so, trass).

Creo que optar por una u otra solución pasa por delimitar qué se entiende por una función sintáctica o gramatical, cuestión que llevaría nuevamente a considerar si es o no pertinente hablar de una «función sintáctica» suplemento, en la misma medida en que se habla de una función sujeto o de una función objeto directo. Tal cuestión requiere, a mi juicio, un tratamiento específico y no voy a entrar en ello. Sí quisiera decir, no obstante, que coincido con Gutiérrez Ordóñez, así como con R. Pérez (1989) o con Bosque (1983), por ejemplo, en que la sustitución por adverbio no parece razón de peso para establecer dos funciones sintácticas diferentes: complemento adverbial (residen en Vigo) y suplemento (el problema estriba en su falta de escrúpulos). No conviene olvidar, además, que, como han sugerido Alarcos (1980), Bosque (1989) o Gutiérrez Ordóñez (1997), los adverbios locativos se aproximan en muchos de sus rasgos a los nombres o a los pronombres. 
significado difícil de motivar (confiaba en sus amigos, insistía en su inocencia); construcciones en las que la unión entre el verbo y el complemento preposicional parece responder a un proceso de lexicalización (dio con la solución) y construcciones en las que ni el verbo forma parte de una clase semántica distinta ni parece variar su sentido en función del complemento (he soñado con él, he soñado que me perseguía) ${ }^{7}$.

Ahora bien, el hecho de que aún quede mucho por analizar en el ámbito de los papeles semánticos vinculados al objeto preposicional no supone, claro está, que este aspecto no haya sido objeto de atención, y no sólo en relación con los papeles —《origen», «ruta», «meta» o «dirección», «ubicación»- vinculados a verbos de movimiento o de posición, en los que parece más clara la conexión entre papel semántico, preposición y significación verbal. También han sido — directa o indirectamente - tratados, particularmente desde el punto de vista de sus relaciones con los papeles asociados al objeto directo, los contenidos de los objetos preposicionales «abstractos», esto es, sin contenido «espacial»o, al menos, sin un contenido «espacial» claro.

\section{Sobre las interpretaciones de los objetos preposicionales}

Ciertamente, ni se encuentran ni cabe esperar ${ }^{8}$ alusiones a papeles semánticos en los trabajos sobre el suplemento u objeto preposicional que se sitúan en el marco de un funcionalismo estructuralista formalmente orientado. Así cuando Alarcos, en sus ya clásicos trabajos sobre el suplemento, o Martínez (1986) plantean la equivalencia entre objeto directo y suplemento - tan repetida, con diferentes matices en otros trabajos ${ }^{9}$ - en cuanto a la relación semántica que establecen con el

7 De conformidad con Porto Dapena (1987: 136): «no parece muy aconsejable meter en el mismo saco los casos de fijación preposicional, en los que la preposición juega un mero papel diacrítico (dar con una cosa, acordarse de algo (...) y tantísimos otros verbos con régimen sólo explicable diacrónicamente, junto con aquellos casos en que la preposición cumple su normal función de establecer un determinado tipo de relación». Pero, de hecho, atendiendo a la valencialidad y a la condición de elemento preposicional, es muy amplio el conjunto de elementos, diferentes en muchos otros aspectos, que se incluirían en la clase objeto preposicional o suplemento.

Dado el «formalismo» que ha venido caracterizando a este marco; un formalismo en el que, a juicio de Rojo (1994: 20), «se halla la razón de la que me parece otra gran ausencia del estructuralismo funcionalista: las funciones semánticas». No obstante, según afirmaba Gutiérrez Ordóñez (1997b: 472), aunque en el modelo clásico de sintaxis funcional «había un conjunto de razonamientos proscritos: los que aludían al contenido», «el Funcionalismo es una disciplina flexible y dúctil a las innovaciones», de ahí que «sin olvidar ni desmontar las antiguas conclusiones, se inician labores en una nueva planta: el nivel de las funciones semánticas».

9 Es curioso que, por ejemplo, Hernanz y Brucart (1987: 262), aunque parten de un marco generativo, planteen, en términos muy similares a los de Alarcos, que «la relación existente entre el CP y el verbo 
verbo, no cabe deducir referencia alguna a la equivalencia de papel semántico, según los sentidos que tiene actualmente el término. Sólo quieren decir que ambos «puntualizan la alusión léxica de la raíz verbal» (Alarcos, 1994: 276), «especifican la referencia real del significado léxico del verbo» (Alarcos, 1994: 282); que los suplementos, al igual que los «implementos», «concretan semánticamente, de forma directa, la noción léxica del verbo» (Martínez, 1986: 57). Plantear, por tanto, que los objetos preposicionales de hablar de política, confio en mis amigos, recurrió a una organización o las circunstancias familiares influyeron en su carácter son equivalentes a objetos directos «porque concretan semánticamente la noción léxica del verbo» no supone admitir, asimismo, un papel de «paciente», por ejemplo, en todos ellos.

Pero también, como es sabido, las relaciones semánticas entre el verbo y algunos tipos de objetos preposicionales o suplementos «abstractos» - hablar de política, confio en mis amigos, he soñado con él, discrepo de sus opiniones, renunció a su puesto entre ellos (dejo al margen cuestiones relacionados con los papeles de los complementos en construcciones pronominales)-, sus semejanzas o desemejanzas con las que se establecen entre verbos y objetos directos, han sido descritas mediante términos tales como 'paciente', 'tema' o conceptos como 'dirección', 'finalidad', 'campo' o 'situación nocional', 'origen', 'copresencia' que sí remiten al ámbito de los papeles semánticos, de los papeles asociados a los términos en el estado de cosas designado por el predicado.

2.1. Así, por ejemplo, Demonte $(1989,1991)$ o Gràcia i Solé (1989) —aunque su estudio se refiere al catalán creo que sus plantemientos pueden trasladarse fácilmente a las construcciones castellanas equivalentes - se han ocupado de los papeles que pueden asociarse a los complementos de, por ejemplo, hablaba en catalán, renunció a su puesto, confio en ellos, soñó con una tormenta, pugnan por un sitio adecuado, prescindirá de sus servicios, en Joan parlava del Congrès, el cel resplandeix d'estrelles, ningú no confia en el ministre, no he pensat en vosaltres, la comissió discutirà del problema d'en Joan.

Tanto Demonte como Gràcia parten del modelo generativista Principios y Parámetros, en el que, como se ha indicado ya, los papeles temáticos o semánticos asociados a los argumentos internos del verbo, o a las «posiciones de argumento» ${ }^{10}$, se han erigido en noción clave, dadas las vinculaciones que se han establecido entre

presenta paralelismos notables (...) con la que media entre este y el OD», si bien el paralelismo sí parece hacerse extensivo, en este caso, al «papel temático».

10 Con palabras de Gràcia i Solé (1989: 132): «els papers-theta s'assigen a posiciones estructurals posicions-theta- i no directament als elements lèxics que les ocupen». 
ellos y las configuraciones sintácticas o realizaciones estructurales ${ }^{11}$. De ahí que, según señalaba Demonte, haya sido un problema destacado en el modelo Principios y Parámetros tratar de dilucidar «por qué en numerosos casos en que el verbo toma un único argumento este no se realiza de manera directa, sino que requiere una preposición» (1991b: 32), o por qué un mismo verbo (cargar, pensar, por ejemplo) puede proyectar en configuraciones sintácticas distintas sus argumentos (1991b:33): pienso que todo ha terminado, pienso en el paso del tiempo; dos cuestiones que, evidentemente, afectan a los objetos preposicionales «directos».

Dado, por otro lado, el estatus que se confiere a los papeles semánticos en este marco, parece necesario que la asignación de papeles se haga de un modo definido y claro, que los papeles estén suficientemente delimitados. Como advertía Gràcia i Solé (1989: 306), «no n'hi ha prou a dir que un argument rep un paper-theta sinó que cal decidir quin és aquest paper-theta».

Sin embargo, quizá sea ya un indicio del carácter problemático de estos complementos y su posible papel semántico el hecho de que, aun partiendo del mismo marco, Demonte y Gràcia, parecen llegar a conclusiones distintas en el análisis de algunos casos. No en vano, según señalaba Gràcia (1989: 55), «l'assignació de paper-theta als SPs regits pels verbs és una altra d'aquelles quiestions que no queden del tot clares a la bibliografia».

2.1.1. Para Gràcia i Solé, entre cuyos objetivos figura delimitar los papeles semánticos de los argumentos que «nacen» en la posición de objeto, es 'tema', por ejemplo, el papel semántico que conlleva el complemento introducido por de en en Joan parlava del Congrès, entendiendo como 'tema' el papel, distinto de 'paciente' 12 y de 'resultado' u 'objeto efectuado', que correspondería a «l'element on s'esdeve un estat de coses sense que ell en sigui l'originador ni el terme» ${ }^{13}$. Es asimismo 'tema' el papel de los complementos de «gaudeix», «discutirà» en los ejemplos siguientes, ya se realicen como $\mathrm{SN}$, en Joan gaudeix la vida, la comissió

11 En términos de Demonte (1991b: 69), por ejemplo, la subteoría de la gramática que se ocupa de la realización sintáctica de los argumentos «parte de la premisa de que hay una notable correlación entre ciertos aspectos del significado de los predicados y la forma de las oraciones en que ellos pueden aparecer». Con palabras de Gràcia (1989: 115): «l'estructura formal i categotial dels arguments d'un nucli assignador de paper-theta (...) es desprendran de la seva estructura temàtica: cada un dels paperstheta s'assignarà a un argument de la categoria i amb l'estructura que dicti la seva REC» (REC: Realización Estructural Canónica).

${ }_{12}$ Aunque 'tcma' y 'paciente' son papeles que el núcleo verbal asigna directamente -o a través de una preposición «transparente»— a los argumentos «que neixen a la posició d'objecte» (1989: 319) son, desde su punto de vista, papeles diferentes. 'Paciente' figura entre los «termes directes» (1989: 311); no es oracional, alude a algo que tiene existencia independiente y recibe las consecuencias del estado de cosas.

${ }_{13}$ Otros ejemplos de 'tema' serían, según su análisis, los subrayados en los ejemplos siguientes: en Joan té una casa, la taula pesa deu quilos, la carta va arribar estripada (1989: 314). 
discutirà el problema d'en Joan, ya aparezcan como de+SN porque «el verb esta marcat com a intransitiu» (1989: 318): en Joan gaudeix de la vida, la comissió discutirà del problema d'en Joan. Es igualmente 'tema' (o 'paciente') el SN introducido por de en el cel resplandeix d'estrelles (1989: 321) $)^{14}$ y mantiene el mismo papel en l'estrelles resplandeixen en el cel. Así pues, los 'temas' y «potser també els Pacients» (1989: 319) no sólo se realizan mediante un SN, sino también, en ciertos $\operatorname{casos}^{15}$, mediante un $\mathrm{SN}$ introducido por de, una preposición «semánticament neutra», «transparent» (1989: 317-318) que se limita a transmitir ${ }^{16}$ el papel semántico que asigna el verbo, como núcleo, a su argumento interno.

Pero si bien a-La Maria es va acostumar a la bona vida-, en -Ningú no confia en el ministre, No he pensat en vosaltres (1989: 58)- , incluso amb, se mencionan, al igual que de, entre las preposiciones que introducen complementos —de carácter no «espacial»—regidos por el núcleo verbal, no se nombran ya entre las posibles realizaciones del papel 'tema' implicado en la red temática verbal ${ }^{17}$. No serían, pues, 'temas' a la bona vida, en el ministre, en vosaltres; y aunque tampoco parece decantarse Gràcia por ningún papel semántico «oficial»-al menos yo no he podido colegir por cuál ${ }^{18}$-, sí plantea en algún momento que, en los complementos preposicionales regidos que, frente a los complementos «locales» de verbos como venir o anar, no tienen «un valor tan evident», «potser caldrà admettre que els papers-theta correspondran també a Orígens, Direccionals o Locatius, agafats en un sentit abstracte» (1989: 62). Así tendrían la forma adecuada para un 'locativo' $(e n+S N)$ o para un 'direccional' $(a+S N)^{19}$.

\footnotetext{
14 La preposición se explica en este caso porque el verbo no asigna caso a la posición de objeto ni papel-theta al sujeto.
}

Según su planteamiento, cuando el verbo es intransitivo el papel semántico 'tema' requerido por el verbo se realiza como $d e+S N$. Pero también, por ejemplo, parece apuntar (1989: 62) que el complemento de «abstenirse» podría entenderse como 'origen' tomado en un sentido abstracto.

is La asignación sería composicional, realizada conjuntamente por el verbo y la preposición, como correspondería, según sus planteamientos, a los complementos regidos (1989: 55 ss.), pero en estos casos, según Gràcia, no cabría hablar de composicionalidad desde un punto de vista semántico, sino sólo «estructural».

17 Tras comentar que no es de extrañar que sea precisamente de la preposición que introduce un tema, «ja que sempre s'ha dit que era la preposició més neutra semànticament» (1989: 63), añade que «alguns autors han ampliat aquesta propietat a la preposició a que, en alguns casos, també sembla buida» (ibid.) Pero, aduciendo la inexistencia de alternancias complemento directo-complemento preposicional introducido por $a$, rechaza esa posibilidad, sugiriendo que «alguna diferència hi ha entre les dues suposades pseudo-preposicions» (ibid.).

18 Gràcia i Solé parece evitar afirmaciones concluyentes cuando se trata de hablar sobre el significado de la preposición, sobre su intervención en la asignación del papel, así como sobre la misma identidad del papel.

${ }_{19}$ Y la asignación sí debería ser, en este caso, «semánticamente composicional». 
2.1.2. Desde el punto de vista de Demonte, estaríamos ante un 'tema' o 'paciente' -término que, a diferencia de Gràcia, utiliza en un sentido amplio, que abarca 'objeto afectado' ('cambiado', 'efectuado', 'desplazado' o 'tema' en sentido estricto) y 'objeto no afectado' (1991b: 37-38) — en los complementos introducidos por de con verbos como discutir ${ }^{20}$ o disfrutar que alternan ${ }^{21}$ la variante «directa»y la preposicional. Es asimismo 'paciente' o 'tema' el complemento, introducido igualmente por de, de verbos como discrepar, prescindir, desconfiar, abusar ${ }^{22}$, que no parecen admitir ya la alternancia entre variante transitiva y variante preposicional, aunque Demonte parece aceptar en algún caso esa posibilidad ${ }^{23}$.

También, por último, parece interpretar como 'paciente' o 'tema' el papel de complementos regidos introducidos por en, a, por, con: si es 'paciente' o 'tema' el papel que corresponde al SN en hablar catalán, pensar una palabra, soñar una tormenta, el papel no variaría en hablar en catalán, pensar en una palabra, soñar con una tormenta ${ }^{24}$, aunque sí medie entre ambas construcciones una diferencia «aspectual». Sería igualmente 'paciente' o 'tema' el complemento preposicional regido por renunciar (renunció a su puesto), insistir (insistió en su afirmación), incurrir (incurre en los mismos defectos), pugnar (pugnar por su sitio), influir (en) confiar (en), optar (por), aspirar (a), acceder (a) o incluso pelear (por).

20 No menciona expresamente el verbo discutir — sí disfrutar - pero creo que puede incluirse en la segunda de las dos clases de verbos preposicionales que delimita Demonte (1991).

21 «A la clase pensar/pensar en pertenecen tambien formas como hablar/hablar en o disfrutar/ disfrutar de. Lo relevante de estas formas en relación con nuestra hipótesis es que si bien la estructura argumental de ambas expresiones es siempre la misma (el objeto tiene en todos los casos el papel temático de Tema y el sujeto es un Agente o Experimentante), la diferencia entre la variante preposicional y la otra tiene que ver con la manera como se concibe la acción verbal» (1991: 105).

Aunque menciona en nota (1991: 72) depende de como construcción perteneciente a la misma clase, quizá se trate de una errata porque más adelante $(1991: 78,80)$ se refiere a la representación de la estructura de María depende de si misma como candidata a representar las construcciones de la clase (1), no de la clase (2) en la que se incluye inicialmente. Por lo demás, tampoco parece ajustarse a los rasgos que da como característicos de la clase (2). No admite una interpretación agentiva y, según el DRAE sólo se utiliza como intransitivo.

2.3 Demonte menciona como peculiaridad de la clase (2), en la que se incluirían las construcciones con los citados verbos, el hecho de que algunos de sus miembros permitan una variante no preposicional Pero no sólo no parece claro que admitan esa variante insistir, incurrir, discrepar, alardear, pugnar, optar sino tampoco abusar, prescindir o renunciar, a los que se refiere expresamente la autora como verbos que admiten esa posibilidad. Prescindir, abusar son señalados por el DMILE como verbos intransitivos únicamente. Renunciar, según el DUE, puede usarse como transitivo - renunciar algo en otro-, pero añade que sólo es usado con $a$; según Cano Aguilar (1999), el uso transitivo directo con este verbo, heredado del latín, es ya un arcaísmo. De hecho, el presidente renunció su puesto en el noveno congreso (1991: 108) resulta una construcción extraña, tanto para mí como para los colegas que he consultado.

24 Aunque alude a la «diferente naturaleza del tema como consecuencia de la distinta manera de ser de la acción» (1989: 95). 
$\mathrm{Al}$ menos, todos ellos los incluye Demonte entre las construcciones con verbos preposicionales de la clase $(2)^{25}$, una clase que, a su juicio se caracterizaría por, entre otras, las siguientes propiedades: los verbos «son idénticos a los verbos acusativos convencionales, aunque algunas veces su argumento interno aparezca precedido de preposición» (1991: 77), «se alinean con los verbos transitivos regulares» $(1991: 112)^{26}$; las preposiciones que encabezan los complementos, son preposiciones «falsas», que «aparecen típicamente en estructuras argumentales de Agente-Paciente» (1989: 95), que no intervienen en la configuración del papel temático del complemento, ni siquiera composicionalmente. Son «una marca de una variante del caso acusativo (un «acusativo preposicional») que surge condicionada por las propiedades aspectuales del predicado verbal» (1989: 95); o, como dice en otro lugar, «la preposición se adjuntaría al SN para expresar los rasgos aspectuales del núcleo de un $\mathrm{S}$ (intagma) $\mathrm{A}$ (spectual)» (1991: 106), dado que entre las construcciones con complemento directo y las construcciones con complemento preposicional no habría diferencia de estructura argumental Agente-Paciente, como se ha indicado ya-, sino sólo diferencia aspectual: acción delimitada (pensó una palabra), acción no delimitada (pensó en una palabra) ${ }^{27}$.

Queda ya dicho que Demonte entiende el concepto de 'paciente' (o de 'tema', puesto que a veces utiliza ambos términos indistintamente), como papel vinculado a la posición estructural de argumento interno, en un sentido más amplio que Gracia i Solé; pero puede colegirse también de lo dicho —obviando por el momento las cuestiones «aspectuales»- que Demonte consideraría 'pacientes' o 'temas ${ }^{28}$ complementos preposicionales como los de pugnar, renunciar, incurrir,

25 En la clase (1) se incluyen construcciones como constar de, redundar en, prorrumpir en, abogar por, consistir en, reposar en. La clase se caracteriza, entre otros rasgos, porque, a su juicio, el complemento es un predicdo en una cláusula reducida; la preposición, a diferencia de la que encabeza los complementos de la clase (2), es una "preposición verdadera» que, como las de los adjuntos, sí asignaría papel semántico al complemento. No obstante, en su análisis no hace referencia a cuáles serían, en cada caso, los papeles semánticos.

Como plantea Demonte, parece razonable aceptar que no todos los elementos que, en razón de la valencialidad, se han clasificado como complementos preposicionales regidos, admiten un mismo análisis, dada la extensión y la heterogeneidad de la clase. Los fundamentos de su clasificación están muy vinculados, no obstante, a supuestos propios del modelo teórico del que parte.

26. Refiriéndose al carácter ciego del caso estructural (1989: 163), afirma que un objeto directo puede ser 'paciente', 'meta', 'origen', 'locación' etc. Pero no he encontrado entre sus ejemplos objetos directos con el papel del 'origen', por ejemplo. Establece, además, (1991b: 41) la generalización siguiente: «Los verbos transitivos proyectan preferentemente un objeto directo paciente (afectado o no afectado), de no ser tal ese objeto es una Locación delimitada».

27 El análisis de Demonte es asumido también, en términos generales, por Fernández Lagunilla y Anula Rebollo (1995).

28 Para Hernanz y Brucart (1987), también construcciones del tipo de discutieron del problema, soñar con Granada, contamos con la ayuda de Juan, optó por el premio en metálico, confías demasiado en la vecina, la empresa se avino a la negociación, parecen entenderse como construcciones con 
optar, aspirar, confiar que, según he creído entender, no interpretaría como tales - al menos de un modo claro- Gràcia. Cabría señalar, además —aunque quizá pueda parecer algo marginal- que si Gràcia considera 'tema' (un papel, no lo olvidemos, vinculado al objeto directo) el complemento de parlava del Congrès, Demonte asigna también el papel de 'paciente' o 'tema' al complemento de hablar en catalán, cuando ambos tipos de complemento pueden coexistir en una misma construcción oracional (hablaba del Congreso en catalán), y la relación semántica entre verbo y complementos no por ello parece variar ${ }^{29}$.

2.2. Fuera de ese marco teórico concreto, el contenido de la relación que se establece entre verbo y complemento preposicional - en qué casos se aproxima al concepto tradicional de 'paciente', cuándo puede describirse como una relación de 'origen' o 'direccional', etc.- ya fue tratado por Cano Aguilar (1981) en su aproximación a la transitividad «preposicional»y, más recientemente, ha vuelto a ocuparse de ello en el capítulo de la Gramática descriptiva de la Lengua Española (Bosque y Demonte, 1999) dedicado a los complementos preposicionales de régimen verbal (Cano Aguilar, 1999). Asimismo, los aspectos semánticos de las construcciones con complemento preposicional, sus relaciones con la transitividad, han sido abordadas, partiendo de un enfoque funcional —en el sentido amplio del término- por García-Miguel (1995) en su estudio sobre la transitividad y la complementación preposicional.

$\mathrm{Ni}$ García-Miguel ni Cano Aguilar tratan de dar respuesta a problemas de «proyección» sintáctica de argumentos, ni parecen asumir, como postulado, que las realizaciones sintácticas sean absolutamente predecibles a partir del significado y la estructura argumental de los verbos. Sus análisis no tienen, en realidad, muchos puntos de contacto con los que, como era el caso de los de Demonte y Gràcia, parten de planteamientos propios del modelo Principios y Parámetros. Pero presentan también una interpretación sobre casos que ya anteriormente hemos mencionado como ejemplo: discutir (de), hablar (de), confiar (en), aspirar (a), renunciar (a) y otros muchos casos concretos. De manera que podemos comparar sus análisis sobre el valor de la preposición o sobre el significado «relacional» del complemento para calibrar, mínimamente al menos, qué tipo de problemas puede

\footnotetext{
preposiciones vacías, puras marcas de caso (1987: 263), en las que el verbo asigna al complemento el papel semántico de 'tema' o 'paciente', el mismo que se asocia al objeto directo. La distinción de papeles semánticos no es, no obstante, un aspecto específicamente abordado en este trabajo; la empresa se avino a la negociación es el único ejemplo de complemento preposicional en el que se concreta el papel semántico ('tema', como ya se ha indicado). Pero, según se mencionó en una nota anterior, sí hablan de un paralelismo entre complemento directo y complemento preposicional que parece hacerse extensivo al papel semántico.
}

29 Recuérdese que, según los planteamientos del modelo que asumen, el verbo no puede asignar el mismo papel temático a dos argumentos. 
presentar el análisis de los papeles semánticos del objeto preposicional o suplemento.

2.2.1. La adecuación a la definición de 'objeto' —esto es, 'paciente'- de la gramática tradicional, como «persona o cosa sobre la que recae la acción verbal» (Cano Aguilar, 1981: 381), la equivalencia, en definitiva, en lo que respecta a la relación semántica entre verbo y complemento, con la transitividad (Cano Aguilar, 1981: 376), constituían para Cano Aguilar atributos de los complementos que catalogaba como «objeto preposicional».

El concepto de «objeto preposicional» utilizado por Cano Aguilar no coincide con la noción, más extensa, designada en otros estudios con ese mismo término, o con las restantes denominaciones - suplemento, complemento preposicional, etc.- utilizadas como equivalentes. Es también más restrictivo que el concepto de «complemento preposicional de régimen verbal» (Cano Aguilar, 1999); no se basa, a diferencia de este, en la centralidad o valencialidad, sino en la pérdida de significado de la preposición ${ }^{30}$. Es este el aspecto que le permite hablar de analogías entre objeto directo y objeto preposicional en lo que concierne a su relación semántica con el verbo. Así en construcciones del tipo hablar de política, soñar con Granada, discutir de política, pensar en una palabra, estaríamos, según indicaba Cano Aguilar, ante «objetos preposicionales», porque la preposición se hallaría vacía de significado ${ }^{31}$; en cambio, en concurrió a la cita, recurrió a sus padres, preguntó por él, el complemento ya no sería «objeto preposicional» pese a estar implicado en la valencia verbal, sino «circunstancial», porque la preposición sí conservaría su significado ${ }^{32}$.

En «Los complementos de régimen verbal» (Cano Aguilar, 1999) no parece que intente diferenciar «objetos preposicionales» de otros complementos

\footnotetext{
30 Según sus palabras (1981: 360), «el criterio fundamental para hablar de transitividad en estas frases es que la preposición no tenga significado propio».

Entre Ios criterios utilizados para justificar el carácter vacio de la preposición y la existencia de transitividad figuran: la analogía significativa con construcciones de objeto directo - acordarse de algo, recordar algo-; la transformación en construcciones «pasivas» o de participio del tipo lo discutido, lo gozado; la alternancia con construcciones de objeto directo sin que haya variaciones significativas en el sentido de la construcción o del predicado: hablar algof de algo; la adecuación a la definición tradicional de 'objeto' o 'paciente', como ya se ha apuntado.

31 Se puede dar «la libre alternancia entre construcción directa y preposicional» (1981: 386): soñar algof con algo; pueden transformarse en construcciones de participio: lo hablado, lo discutido, lo soñado (1981: 476, 387); en construcciones como pensar en ti, pensar en el dinero, es «perfectamente aplicable la definición tradicional de objeto» (ibid.).

32 El complemento de concurrir parece, a juicio de Cano, «más bien locativo que transitivo» (1981: 372); en recurrir a algo, «a conserva valor direccional» (1981: 373). En los complementos introducidos mediante la preposición por, en general la preposición sigue, a su juicio, teniendo sentido, aun cuando se halle muy atenuado (1981: 388 ).
} 
preposicionales de régimen verbal, tomando como base el carácter más o menos vacío de la preposición; ni da «excesiva importancia» a que algunos puedan alternar con objeto directo ${ }^{33}$, sin que varíe demasiado el sentido del verbo o del complemento (1999: 1816), o a otras pruebas que permitan aproximar el complemento preposicional a la transitividad ${ }^{34}$. Antes bien, viene a afirmar que, aunque la elección de la preposición no se haya realizado en virtud de sus significados más usuales, aunque, como consecuencia de ello, «se diluya la función semántica que se puede atribuir al sintagma preposicional» $(1999: 1818)^{35}$, no suele haber pruebas objetivas de que la preposición carezca por completo de sentido (1999: 1815).

Interesa, en cualquier caso, destacar, por lo que atañe a la semántica del complemento preposicional que, por ejemplo, en construcciones como discutir de política, hablar de ello, no considera ya que de sea una preposición vacía, ni habla de equivalencias con el objeto directo; los complementos indican 'tema' o 'asunto' y la preposición «mantiene un cierto contenido que le permite, por un lado, presentar con otros verbos el mismo tipo de complemento» (1999: 1815)—disertar, tratar, murmurar, conversar - y «alternar con otras preposiciones (sobre, acerca de, etc.)» (ibid.).

'Asunto' o 'materia', 'objetivo' o 'tema' de la actividad o del pensamiento denotan también, según Cano Aguilar, algunos complementos de régimen encabezados por en, como confiar en los amigos, creer en el infierno ${ }^{36}$, disiento en esa cuestión ${ }^{37}$, pensaba en su pobre madre ${ }^{38}$, y tal ven incidir o insistir (en lo

33 «Tal cosa revela simplemente que objetos directos y regímenes preposicionales comparten una zona semántico funcional semejante» (1999: 1816).

34 «La posibilidad de que determinados regímenes preposicionales se transformen en construcciones cuasi-pasivas (del tipo soñar con algo $\rightarrow$ lo soñado) o incluso puedan pronominalizarse (quédate con el dinero $\rightarrow$ quédatelo) tendrá en esta exposición un valor evidente, pero secundario; ayudará a caracterizar algunos complementos de régimen preposicional, pero en principio no los definirá» (1999: 1816).

35 Por ello, afirma, la función «más neutra de todas, la de 'objetivo' será la más habitual» (1999: 1818). Pero también apunta en otro lugar que la función semántica del complemento «podría corresponderse más o menos claramente con las 'funciones semánticas' habituales (tampoco este es un catálogo bien definido), y en algunos casos podría corresponder exactamente a ninguna, o ser muy próxima en sentido a lo que en otros enunciados son determinaciones adicionales y accesorias, 'circunstancias' que enmarcan al núcleo del predicado» (1999: 1817-1818).

36 El régimen con en es exclusivo «con determinados verbos de actitud mental en los que viene a señalar el objetivo de dicha actitud: confiar y creen $(1999: 1827)$.

37 Disentir, diferir, discrepar, además del complemento con de «que alude a la opinión de que se aparta», «puede llevar también un complemento de 'asunto' o 'materia' con el que son posibles varias preposiciones» (1999: 1832), en y sobre entre ellas.

38 Pensar, en el sentido de «imaginar», lleva objeto directo 'efectuado', pero en el sentido de «cavilar» o «especular» «el objetivo o tema del pensamiento aparece básicamente introducido por en» (1999: 1833). 
pactado) $)^{39}$. Señala, además, que «el desarrollo de locativos abstractos con los verbos de proceso mental justifica la existencia de pensar en ti o creer en los Reyes Magos» (1999: 1819), aunque ya el complemento no sea sólo un locativo abstracto (1999: 1820$)^{40}$. En cualquier caso, el proceso de metaforización a partir de complementos locativos ${ }^{41}$ no se limitaría a creer o pensar ${ }^{42}$. Está, según Cano, en la base de buena parte de los casos de régimen preposicional, si bien no oculta que se trata de un proceso difícil de comprobar (1999: 1819), cuestiones estas que parecen clave en la interpretación de las relaciones semánticas entre verbo y complemento preposicional.

En los complementos encabezados por a de acceder, propender o aspirar, parece latente, a su juicio, el sentido 'direccional', propio en principio de $a$ (1999: 1825), pero «el régimen con a implica una cierta idea de «separación»o «alejamiento» por ejemplo, en renunciar» (1999: 1824).

En cuanto a los complementos 'exigidos' o 'seleccionados' que se introducen mediante por -entre los que podrían incluirse los de pugnar, optar, al igual que de abogar, separados en la clasificación de Demonte como pertenecientes a grupos de verbos preposicionales diferentes ${ }^{43}$ - mantiene Cano $(1981: 388 ; 1999: 1830)$ que la preposición sigue teniendo sentido: 'a favor de', 'finalidad', 'beneficiario' ${ }^{44}$.

Por último, el matiz de 'origen', 'punto de partida' o 'alejamiento', matiz que parece incompatible con la noción de 'paciente' (o de 'tema') en cuanto que este se conceptúa como término, se halla presente, según Cano Aguilar, en el complemento introducido por de de algunos de los verbos que, en el análisis de

\footnotetext{
39 Aunque «implican más bien actos de decir», los trata Cano Aguilar junto con verbos como pensar y otros «próximos en sentido», como cavilar o recapacitar (1999: 1834).

40 De interpretarse como locativo abstracto, no quedaría claro, a su juicio, por qué «Juan piensa mucho en su pueblo sigue teniendo dos análisis y dos sentidos, según en su pueblo sea el lugar 'donde' se ejerce la acción de pensar o el 'objeto sobre' el que se efectúa el pensamiento» (1999: 1820).

414 ¿O de otro tipo, de carácter 'concreto', 'material'» (1999:1819).

42 También, por ejemplo, de persistir en (sus designios) destaca explícitamente que se trata de una «derivación metafórica del tipo locativo habitual» (1999: 1828).

43 Abogar por se integra en la clase (1), la de los verbos cuyo complemento va introducido por una preposicion «verdadera», que asigna papel temático, en tanto que pugnar por, optar por se incluyen en la clase (2), como ya se ha indicado.

${ }_{44}$ Asimismo, mientras Demonte incluye prorrumpir en sollozos, el capítulo consta de cinco partes entre las construcciones con verbos preposicionales de la primera clase, los que no forman parte de estructuras de Agente-Paciente y llevan preposiciones verdaderas que asignan caso y papel temático, según Cano el régimen en prorrumpir en «se aproxima a la indicación de algo efectuado» (1999: 1828) un valor «propio de los objetos directos» (1999: 1817), mientras que en el libro consta de dos partes la relación semántica entre verbo y complemento resulta, a su juicio, inclasificable (1999: 1817).
} 
Demonte, se alineaban con los verbos acusativos convencionales: desconfiar ${ }^{45}$, abusar $^{46}$, prescindir $^{47}$ o discrepar ${ }^{48}$.

2.2.2. El análisis que plantea García-Miguel (1995) de las relaciones semánticas entre verbos y complementos preposicionales -incluyendo, entre otras muchas, las construcciones que hemos venido mencionando-se halla orientado por los siguientes postulados básicos (1995: 95-100): el carácter significativo de la propia construcción oracional SUJ-PRED-CPREP, distinto del asociado al esquema SUJ-PRED-CDIR, propio de la (alta) transitividad; el supuesto localista de que los sentidos locales de las preposiciones son cognitivamente más básicos y sirven «de plantilla estructural para la conceptualización de otro tipo de relaciones» (1995: 98), como las expresadas por los complementos preposicionales de carácter «más abstracto»; la hipótesis, de raigambre estructuralista, ya planteada por Trujillo (1971) y Morera $(1988)^{49}$, de que las preposiciones tienen un significado básico, necesariamente abstracto, que puede subyacer como invariante, como constante, tanto a los complementos valenciales de sentido espacial (partió de Salamanca, reside en Madrid), como a los «nocionales», más abstractos (prescindió de sus servicios, confia en sus amigos), aunque el sentido varíe en función del significado del predicado (1995: 99).

Así, por ejemplo, si la preposición en significa 'situación absoluta', ese significado se hallaría evidentemente implicado en construcciones como reside en Oviedo o escarbó en la tierra, en las que el complemento tiene sentido local y denota la situación física en que tiene lugar el evento o se realiza la actividad. Pero estaría asimismo presente, no sólo en construcciones como escarbar en los secretos ajenos, clara extensión metafórica del sentido anterior de escarbar, en la que sólo cabe una interpretación nocional - 'campo nocional' en el que se aplica la actividad (1995: 141)—, sino también, por ejemplo, en confío en vosotros, pienso en mi vida, creo en los marcianos; el complemento expresaría, a su juicio, la situación no física del acto (1995: 144), si bien estas construcciones no parecen guardar actualmente relación con otros sentidos más básicos.

Del análisis llevado a cabo partiendo de tales postulados, parece deducirse que el papel de 'paciente', en tanto que elemento 'efectuado' - soñaba que me

\footnotetext{
45 En desconfie de las advertencias «está presente el matiz de origen» (1999: 1826).

46 «El sentido de origen que haría ver en estos casos de régimen dicha función semántica es el que se encuentra en el complemento con de de ciertos verbos construidos con el prefijo ab» (1999: 1826), como abusar de su hospitalidad.

47 Sentido, si no de origen, de «alejamiento» es el que presentaría el complemento de prescindir, así como el de renegar o desistir (1999: 1826) (véase asimismo Cano Aguilar, 1981: 375).

48 'Origen' o 'punto de partida' de «la diferente opinión» expresa el complemento con de de verbos que como discrepar o disentir significan «tener distinta opinión»(1999: 1832).

49 En ellos se basa para los contenidos de las preposiciones «sin que esto suponga necesariamente adhesión a sus puntos de vista sobre la categoría» (García-Miguel, 1995: 100)
} 
perseguían, pienso que me están engañando ${ }^{50}$ - o (totalmente) afectado - escarbó la tierra- por la acción o el proceso designado por el predicado, dominio de llegada o término en la orientación del evento que se inicia en el sujeto (véase García-Miguel, 1995b: 92), sólo puede asociarse al esquema transitivo, a la construcción con objeto directo.

Al complemento preposicional de carácter no local, en cambio, se asocian, en primera instancia, diferentes sentidos - 'campo nocional', 'situación no física del acto', 'tendencia nocional', 'causa', 'motivo' u 'origen nocional', etc. - que dependen, tanto del significado de la preposición, como del significado del predicado ${ }^{51}$.

Así, por ejemplo, en optar a, aspirar a y «su antónimo renunciar a» (1995: $183)^{52}$, a marca el «punto de referencia final» $(1995: 196)$, «la frase que denota la situación o condición a la que se desea llegar» (1995: 183), sentido este acorde con el valor directivo asociado a la preposición $a$.

En soñar con, destaca el significado 'copresencia', propio de la preposición con $y$, aunque no es más explícito sobre el sentido de la complementación ${ }^{53}$, sí viene a resaltar que el papel de 'objeto efectuado' sólo conviene al complemento directo -no al preposicional- de soñar.

Con pugnar por, o pelear por, la preposición, en un uso nocional, «marca el estado u objeto que se pretende alcanzar o la persona a la que se quiere favorecer (beneficiario)» (1995: 206) ${ }^{54}$. En el caso de optar, sería el sentido 'elección', acorde con el significado del predicado, el que se hallaría actualizado ${ }^{55}$. Coincide,

50 «EI CDIR de pensar ( y soñar) no es independiente del proceso; se trata de un objeto efectuado» (1995: 145).

51 «Por su carácter valencial es necesariamente el predicado el que impone en qué sentido debe interpretarse la relación, aunque esta restricción afecta sólo al sentido» (García-Miguel, 1995: 99).

52 Para Morera, con aspirar la preposición conserva su significación de «tendencia»; expresa la dirección de la pretensión (Morera, 1988: 199). En cambio en renunciar a estamos «ante una fijación histórica, donde la preposición ha perdido su significación paradigmática, conservando solamente la función sintagmática» (Morera, 1988: 209).

53. En realidad, al tratar de la complementación preposicional de soñar casi se limita a citar lo que dice Morera (1988) al respecto.

54 Si Demonte presenta peleó por su puesto y peleó su puesto (1991: 108) como cjemplo de alternancia entre complemento preposicional y complemento directo que manifiesta una diferencia de aspecto (no delimitación - delimitación del evento), según García-Miguel ni pugnar ni pelear, ni otros verbos similares como luchar o combatir, admiten conmutación CPREP - CDIR «manteniendo el mismo predicado. La única modalidad de transitividad que parecen admitir estos verbos es un objeto interno» (1995: 207).

55 Comenta sobre el sentido de «elección» que «parece derivarse del de concurrencia o concomitancia entre procesos que puede adquirir la preposición por, y creo que también puede relacionarse con los usos espaciales (con paráfrasis del tipo "proceso a través del cual comienza, continúa o termina una actividad'» (1995: 210). No obstante, advierte inicialmente que, quizá por su doble origen (de PER y PRO), la disparidad entre los usos espaciales y los nocionales de por hace «difícil establecer un punto de 
pues, con Cano en que por no es en absoluto una preposición carente de significado.

En cuanto a los complementos introducidos por $d e$ - ya antes se han mencionado ejemplos de complementos encabezados por la preposición en-, como discutian de política, disfruta de la vida, dudo de sus intenciones, desconfio de todos, prescindió de sus servicios, discrepo de su opinión, rebosa de salud ${ }^{56}$, resplandecía de felicidad - construcción que podríamos considerar similar a el cielo resplandecía de estrellas - el sentido de la complementación se vendría a identificar — coincidiendo, pues, sólo en parte con Cano Aguilar-con el de 'origen', 'punto de referencia inicial', acorde con el significado 'eféresis', 'límite inicial', que correspondería a de en el sistema preposicional, significado que el verbo orientaría hacia el sentido 'origen nocional' (causa inmediata o motivo) o partitivo (1995: 125). No serían, por tanto, 'pacientes', es más, a juicio de GarcíaMiguel, «el significado de la preposición de sitúa a los CPREP(de) en una posición previa en la direccionalidad de las relaciones casuales y/o espacio temporales» (1995: 127-127); por ello, "difícilmente puede convertirse el CPREP en término inherente del evento» (ibid.), cosa que sí ocurre con el 'paciente' representado por el objeto directo.

Si sentidos como 'situación no física', 'dirección' o 'tendencia nocional', 'causa inmediata' u 'origen nocional', etc., pueden corresponder «en primera instancia» a complementos preposicionales de carácter no local, como los que, a título de ejemplo, se han ido mencionando con anterioridad, sugiere -en nota- GarcíaMiguel, además, que el término 'referencia' —utilizado por Dik para designar la función semántica de «the second or third term of a relation with reference to which the relation is said to hold» (Dik, 1997: 121) - quizá sea el más adecuado para reflejar, en general, el contenido del complemento preposicional (García Miguel, 1995: 184). Así aspiro al puesto, confío en ti, discrepo de sus opiniones coincidirán en señalar un punto de referencia con respecto al cual se desarrolla la actividad; referencia 'inicial', en un caso - discrepo de sus opiniones - , en otro aspiro al puesto-, final; en confío en ti, como límite en que se incluye la actividad. El papel de 'referencia', en cualquier caso, sigue siendo diferente del papel de 'paciente', al menos en el sentido que anteriormente le hemos asociado: término o dominio de llegada del evento que se inicia en el sujeto, efectuado o (totalmente) afectado por la acción o el proceso.

conexión que permita entender los usos nocionales como simple adaptación del significado a contextos no espaciales» (1995: 198).

56 La diferencia entre rebosa de salud y rebosa salud, por ejemplo, estriba, a su juicio, en que en rebosa salud, el CDIR es un tipo de objeto efectuado, mientras que en rebosa de salud el complemento se presenta como causa del estado en que se encuentra el sujeto (García-Miguel, 1995: 107). 
2.3. Al cotejar las interpretaciones sobre las relaciones semánticas entre verbo y objeto preposicional, en la reducida muestra de construcciones entresacadas de los estudios que he venido mencionando, quizá llamen la atención las divergencias que se observan, tanto en lo que concierne al sentido de la preposición, como en lo que respecta al sentido de la complementación, dos aspectos evidentemente conectados.

Así, por ejemplo, en construcciones como disfruta de la vida, discutieron de política, de ha sido considerada, bien una preposición transparente, sin significado (Gràcia, 1989; Demonte, 1989, 1991; Cano Aguilar, 1981), bien, por el contrario, una preposición con contenido, que mantiene un significado básico (García-Miguel, 1995; Cano Aguilar, 1999) y contribuye, de alguna manera, al sentido de la complementación. Y lo mismo puede hacerse extensivo al resto de los complementos introducidos ya por de, ya mediante $a$, con, por, en que se han ido destacando.

En cuanto a los «papeles» que corresponderían a lo denotado por el complemento en el estado de cosas designado por el predicado, las interpretaciones no sólo son diferentes, sino que, en algunos casos, hasta parecen llevar a resultados contrarios.

El complemento de pensar en una palabra, pongamos por caso, se ha considerado 'paciente' (Demonte, 1989, 1991; Cano Aguilar, 1981); pero también 'campo nocional', 'situación' en un sentido abstracto (García-Miguel, 1995) ${ }^{57}$ y quizá 'referencia' en un plano de generalización más alto. Tal vez en estos casos exista una cierta proximidad en la interpretación, dado que la 'situación' (física o no física) supone algún modo de 'afectación' ${ }^{58}$. Pero 'paciente' y 'origen' o 'punto de referencial inicial', los dos papeles que se han asociado a, por ejemplo discrepo de sus opiniones o desconfío de todos, parecen, según ya se ha indicado, sentidos realmente contrarios.

Es de destacar además que, dado que, conforme se señaló, 'tema' y 'paciente' no designan los mismos conceptos para Demonte y para Gracià, el hecho de que puedan identificar como 'tema' el papel semántico del complemento en discutir de política, por ejemplo, no supone que le estén asignando exactamente el mismo papel semántico.

\footnotetext{
57 Quizá se oriente también en este sentido Gràcia i Solé (1989) cuando habla de los «locativos abstractos»

58 Señalaba García-Miguel (1995:142) respecto de construcciones como fallar en o acertar en que «el significado de 'campo en el que se aplica la actividad' que tiene el CPREP con estos verbos explica la proximidad designativa con el CDIR». Piénsese, por otro lado, que para Van Valin y LaPolla (1997), por ejemplo, «location», definido como «a place or a spatial locus of a state of affairs» (1997: 87) es uno de los candidatos a ser asumidos por el macro-rol «undergoer», esto es, «the generalized PATIENTType role» (1997: 141)
} 
Por otro lado, algunas de las nociones utilizadas por Cano Aguilar (1999) y por García-Miguel (1995) para describir el sentido del complemento preposicional 'asunto', 'materia', 'campo nocional', entre ellas- no parecen corresponderse exactamente con ninguno de los papeles semánticos argumentales más usuales en la bibliografía, y quizá tampoco con los que suelen mencionarse como propios de los adjuntos, satélites o circunstanciales ${ }^{59}$. Sus interpretaciones parecen situarse, no obstante, en un nivel más específico, más próximo al significado propio de cada una de las unidades verbales.

También cabría señalar, por último, que el hecho de que, por ejemplo, en construcciones como pensaba en su pobre madre se identifique como sentido del complemento 'tema del pensamiento' (Cano Aguilar, 1999) o 'situación no física del acto' (García-Miguel, 1995) no implica, necesariamente que se trate de interpretaciones distintas; dada la abstracción de las nociones a que se refieren, también se podría pensar que se trata sólo de conceptos próximos pero formulados de manera diferente.

En definitiva, las divergencias - aparentes al menos- que se han ido observando en lo que concierne a la interpretación de los sentidos asociados a los objetos preposicionales «abstractos», podrían llevar a concluir, parafraseando a Dowty (1991: 555) que en este ámbito, como en muchos otros relacionados con los papeles semánticos, usando métodos diferentes y enfatizando datos distintos, se puede llegar a interpretaciones igualmente razonables pero diferentes. $Y$ tal vez no sea extraño, dada la diversidad de los enfoques que se han ido proyectando sobre los dos dominios que están aquí implicados (las preposiciones y los papeles semánticos), así como las muchas cuestiones problemáticas que suscitan ambos campos.

\section{Cuestiones en torno a los papeles semánticos}

A pesar de la importancia que, en calidad de «creatures of the syntax-semantic interface» (Dowty: 1991: 548) han llegado a tener nociones como 'paciente', 'tema', 'agente', 'experimentador', 'locación', etc., no pasa desapercibido el hecho de que la alusión a los problemas que conlleva la definición y delimitación de este tipo de nociones es casi una constante en los trabajos relacionados con los papeles semánticos.

En lo que sigue voy a ir recordando algunas de esas cuestiones problemáticas que rodean su tratamiento, porque quizá, según subrayaba Dowty (1991: 551),

59 Halliday (1985: 142) sí incluye «matter» entre los elementos circunstanciales e indica que cs "particularly frequent with verbal processes, as in they're talking about the weathen». Dik (1997), sin embargo, no parece incluir ni entre los argumentos ni entre los satélites una noción semejante. 
pueda resultar útil advertir «the danger of continuing to take this notion for granted and of assuming that thematic roles are as well motivated as phonemes or phrasemarkers». $Y$ es que, realmente, parece que hay muchos aspectos que perfilar antes de plantear, por ejemplo, un análisis de los papeles semánticos asociados al objeto preposicional «abstracto»; entre ellas, claro está, qué concepto de papel semántico se va a utilizar.

3.1. Una de las observaciones que más se reiteran cuando se habla de los papeles semánticos es la falta de consenso acerca de su naturaleza y su estatus.

Hay, pongamos por caso, sensibles diferencias entre un enfoque de los papeles como primitivos que configuran la red temática de un predicado inanalizado ${ }^{60}$ (poner: [Aggente, tema, ubicación]) - que sería, por ejemplo, el enfoque utilizado por Demonte $(1989,1991)$ o Gràcia i Solé (1989) - y una concepción que los vincule a variables o posiciones argumentales de predicados primitivos en un nivel más abstracto: el de la estructura léxico-conceptual en que se representa la descomposición de los predicados en elementos primitivos recurrentes en la definición de otros predicados (poner: [x causar [y estar en z]]) (véase Dowty, 1991; Jackendoff, 1987; Rappaport y Levin, 1988; Van Valin y LaPolla (1997).

La noción de 'tema', por ejemplo, en tanto que objeto de un cambio de ubicación o de un cambio de estado, podría ser aplicable a elementos distintos ${ }^{61}$ según cuál sea el planteamiento que se ha asumido.

Asimismo, por citar otro aspecto vinculado al concepto de papel semántico, parece claro que pueden derivarse diferencias metodológicas importantes del hecho de que los papeles se conciban como categorías discretas, a las que, simplemente, corresponden o no corresponden los argumentos considerados, o, por el contrario, se conceptúen como un conjunto de propiedades - o de 'implicaciones' (Dowty, 1991) - que configuran un prototipo, pero que pueden variar de forma independiente; de manera que un argumento puede aproximarse en mayor o menor grado, por ejemplo, al prototipo de 'paciente'.

Así, partiendo de una definición de 'paciente' como «things that are in a state or condition or undergo a change of state or condition» (Van Valin y LaPolla, 1977: 85), de el desierto en la patrulla cruzó el desierto sólo se podría decir si es

\footnotetext{
60 En este caso, según señala Van Valin (1996: 102): los papeles «serve as the primary means for representing the meaning of the verb».

${ }_{61}$ Si los papeles son nociones relevantes en ese nivel más abstracto, puede tener sentido que, como sugieren Rappaport y Levin (1988), (el) trigo sea 'tema' de un cambio de ubicación, tanto en cargó el camión con trigo como en cargó el trigo en el camión, o que el camión sea a la vez 'tema' de un cambio de estado y 'meta' de un cambio de ubicación. Pero (el) trigo sólo puede ser 'paciente' o 'tema' en cargó el trigo en el camión e 'instrumento' (Dik, 1980) o 'manera' (Starosta, 1978) en cargó el camión con (el) trigo, si 'paciente' o 'tema' son nociones que se aplican a la red temática de un predicado inanalizado.
} 
'paciente' o no; en este caso, no parece ajustarse a la definición de 'paciente», dado que el desierto no experimenta ningún cambio de condición o estado.

En cambio, si 'paciente' —o 'proto-paciente' -, como plantea, por ejemplo, Dowty (1991: 572) se define como un conjunto de propiedades - «undergoes change of state, incremental theme, causally affected by another participant, stationary relative to movement of another participant, (does not exist independently of the event, or not at all)»—, el desierto, evidentemente, aunque no coincida en todas las propiedades, se aproxima al prototipo de 'paciente': además de ser estático con respecto al movimiento de otro participante, es 'tema incrementativo ${ }^{162}$, puesto que «su referente es coextensional con el desarrollo del evento» (García-Miguel, 1995: 95). Ahora bien, no experimenta un cambio de estado, otra de las propiedades del paciente prototípico presente, por ejemplo, en destruyó el edificio.

Por otro lado, el hecho de que las propiedades puedan variar independientemente, no sólo implica que los argumentos pueden aproximarse en mayor o menor grado al prototipo, sino también que algunos de sus rasgos puedan caracterizan a otros elementos que, no obstante, no se perfilan como 'pacientes'. Según Dowty, por ejemplo (1991: 578), el «cambio de estado» también puede caracterizar a un 'instrumento' o a un argumento 'meta': "The Goal undergoes a change in that it acquires the Theme».

Esta noción de tipo de papel semántico es, pues, más compleja que una noción discreta, aunque, además de ser más difícil de manejar, tampoco está en absoluto exenta de problemas.

En los trabajos sobre los objetos preposicionales que he venido comentando, se ven reflejadas esas dos maneras de concebir los papeles semánticos.

Demonte $(1989,1991)$ y Gràcia (1989) parten de una concepción «discreta»: 'paciente', 'meta', 'locativo', etc., se definen de manera global y los argumentos considerados se asignan, según su adecuación a la definición, a un determinado papel semántico.

García-Miguel, por el contrario, sí parece asumir una concepción prototípica, tanto de la transitividad, como de papeles como 'agente' o 'paciente' implicados en el esquema transitivo. De ahí que si bien admite una cierta proximidad semántica entre construcciones con complemento preposicional y con complemento directo en «cláusulas de baja transitividad», o si bien acepta, por ejemplo, que pueda existir cierta afinidad designativa entre un CDIR y un CPREP(en) por compartir un rasgo +afección (parcial en el caso del complemento preposicional ${ }^{63}$ ), 'paciente', como

62 Tomo de López Meirama (1997) la traducción de 'incremental theme' como 'tema incrementativo'. «La 'inclusión” permite inferir la parcialidad» (García-Miguel, 1995: 150). 
prototipo ligado a la alta transitividad, sólo se asocia al objeto directo ${ }^{64}$ y no al complemento preposicional: la entidad que denota el complemento preposicional no es efectuada, ni totalmente afectada, o no es afectada en absoluto, por el proceso verbal ${ }^{65}$.

3.2. Son también frecuentes en los estudios referidos a los papeles semánticos las alusiones a dos tipos de problemas muy relacionados: por un lado, los que plantea la selección de los criterios que deben servir de base para justificar la existencia de papeles semánticos diferenciados - 'tema' y 'paciente', por ejemplo, o 'paciente' y 'objeto resultante'-; por otro, los problemas que se suscitan a la hora de determinar cuál puede ser el grado de generalización adecuado en la diferenciación y definición de los papeles semánticos.

En lo que concierne a la primera cuestión, parece algo asumido que los papeles, como elementos que ponen en conexión aspectos del significado léxico con la morfología y la sintaxis, han de tener una función en el establecimiento de las reglas gramaticales ${ }^{66}$.

Así 'agente' y 'paciente', por ejemplo, sí parecen papeles semánticos justificados ${ }^{67}$, si se tiene en cuenta que no sólo se vinculan a algo tan 'gramaticalmente' básico como la configuración sintáctica o, en otros términos, la realización de los argumentos como sujeto y objeto directo, sino que también se apela a ellos en muchos otros procesos, como la pasivización, por ejemplo.

Sin embargo, ni el vínculo entre 'papel' y realización gramatical parece tan claro cuando nos apartamos del sujeto y del objeto ${ }^{68} \mathrm{ni}$, en cualquier caso, el tener

${ }^{64}$ En este sentido señala Goldberg (1995: 118) que «Languages differ in how the express noncanonical transitive predicates, such as predicates of possession («have», «own») but languages express semantically canonical transitive predicates by means of a transitive construction».

6.5 Señala, además, la correlación — aunque son rasgos que pueden faltar - de las construcciones con CPREP con otros rasgos de "baja transitividad": sujeto no agente, situación estativa, atelicidad (1995b: 92).

66 Según indica Van Valin (1996: 99), «The thematic relations pointed have to be faithful to their semantic basis but they also have to be sensitive to the demands of grammar». Gràcia i Solé (1989: 130), por su parte, afirma que «El desdoblament d'un paper en dos, si sintàcticamente no te cap correlation és inútil, possiblement no ens inđuiria a cap error, però es crearia una casuistica interminable. I si, contrariament, unim en un sol paper-theta relacions que haurian de ser independents - per criteris sintàctics que responguin a alguna diferència semántica- la interpretació pot resultar inadequada».

67 Con respecto al papel 'agente', por ejemplo, Van Valin y Wilkins (1999) afirman que «since every theory which incorporates a thematic relations component invokes this role, its status as one of the vital elements in linguistic theory and description has gone largely unchallenged».

68 Decía Baker (1992) al respecto que, por ejemplo, «many linguists since Fillmore (1968) agree that thematics factors play a kay role in determining which of the Nps associated with a given verb will be subject of that verb. If a morphologically simple verb selects several arguments, one of which is an agent NP that NP will be the subject. This generalization is exceptionless in English; it has also been found to be valid in many other languages» (1992: 22); pero tambié añade que «in other subdomains 
repercusiones gramaticales deja de ser un criterio problemático. Como señala Dowty (1991: 561), «the variety of semantics distinctions that correlates with syntactic and lexical patterns in one way or another is surely enormous. To postulate thematic role types for each of them is quite possibly to dilute the notion beyond its usefulness, but what we lack is a principled way to decide what kind of data motivates a thematic role type».

Así, por ejemplo, si complementos del tipo comer pizza, hablar inglés, son, siguiendo a Van Valin y LaPolla (1997: 122-123), argumentos inherentes, no referenciales, pues no refieren específicamente a ningún participante sino que 'caracterizan' la naturaleza de la acción, expresando una faceta del significado del verbo; si, además, difieren de los referenciales en aspectos gramaticales como la libertad de omisión, la tendencia a la incorporación y las repercusiones aspectuales, podría estar justificado asignar a estos elementos un papel distinto del de 'paciente', aunque coincidan en su realización como objeto directo. El papel «range», por ejemplo, utilizado por Halliday (1985) parece recoger el carácter especial de estos «objetos».

Puede ser razonable, como planteaba Gràcia i Solé (1989: 263), incluir en papeles diferentes ('paciente' y 'tema') los complementos que sólo se realizan como SN y los que admiten una realización oracional, puesto que el configurarse como oraciones o como SN es ya una diferencia gramatical, aunque puedan existir, además, otras diferencias en cuanto a la posibilidad de pasivización. Puede estar igualmente justificado, por su repercusión «gramatical», separar en catalán 'paciente' o 'afectado' y el 'objeto resultante' o 'efectuado' como papeles semánticos si se pueden asociar con distintas posibilidades de derivación (Gràcia $\mathrm{i}$ Solé, 1989: 269); aunque, por otro lado, dado que 'paciente' y 'objeto efectuado" coinciden en realizarse como objetos directos y en admitir la pasivización también sería razonable su agrupación.

En definitiva, como se ha indicado, pueden ser muchas y de diversa índole las diferencias calificables como «gramaticales» que se asocian a distinciones del significado y, en cualquier caso, el hecho de que los criterios no estén en absoluto claros queda de relieve cuando se observan las discrepancias sobre la pertinencia de diferenciar, por ejemplo, 'tema', 'paciente', 'objeto interno', 'objeto resultante' o recurrir a un solo papel semántico 'paciente' o 'tema' para dar cuenta de todos ellos. Al fin y al cabo, según señalaba Van Valin (1996: 99), «different theories and approaches have proposed inventories ranging from three to several dozen thematic relations» y es de suponer que se pueden aducir razones gramaticales para los dos extremos.

there has been considerable less consensus. Indeed the problem of predicting from simple thematic distinctions which arguments will be direct objects and which will be obliques seems to be a much harder one». 
Volviendo a los análisis de los objetos preposicionales que anteriormente se han comentado, cabe considerar que si las correlaciones gramaticales que pueden servir de base para la diferenciación de papeles semánticos pueden ser de índole diversa, podría estar «gramaticalmente» justificado, por ejemplo, asignar a los complementos de he soñado con éll he soñado que me perseguia, he pensado mucho en ti/ he pensado que no valía la pena, un mismo papel semántico 'paciente', entendido en un sentido amplio que abarque tanto objetos afectados (cambiados, efectuados, desplazados) como objetos no afectados (Demonte; 1991b: 37-38).

Pero lo es cierto es que, además de las diferencias de sentido que ya hemos apuntado - el objeto directo de soñar o de pensar se entiende como 'efectuado'; el objeto preposicional, en tanto que 'asunto', 'materia', 'campo nocional' ${ }^{69}$, no es, claro está, un objeto efectuado- también existen entre ambos tipos de construcción — como en otras alternancias objeto directo - objeto preposicionaldiferencias gramaticales: no sólo, según indica García-Miguel (1995:145), como objetos directos «tenemos siempre constituyentes que denotan entidades gramaticales de tercer orden: cláusulas o nombres que en este contexto pueden hacer referencia a 'ideas'», sino que también sólo el 'objeto efectuado' se realiza, al fin y al cabo, como objeto directo en construcción transitiva y admite, por consiguiente, el clítico de acusativo o la transformación en frases «cuasi-pasivas» del tipo lo pensado, lo soñado ${ }^{70}$.

Por lo tanto, también por razones gramaticales parece justificado que los complementos de he soñado con él/ he soñado que me perseguía, he pensado mucho en ti/ he pensado que no valía la pena no queden englobados en el mismo tipo de papel semántico.

En las divergencias en torno al mayor o menor número de distinciones que cabe establecer en el inventario de los papeles semánticos, está implicado el segundo problema que he mencionado: el grado de generalización adecuado; o, en otros términos, como planteaba Dowty (1991: 554), ¿dónde parar en el proceso de abstracción que conlleva la definición de los papeles semánticos?.

Parece ciertamente admitido que si los papeles se postulan como elementos válidos para el establecimiento de reglas gramaticales, deben formar inventarios limitados y denotar generalizaciones extensivas a clases semánticas de

\footnotetext{
69 El complemento de soñar introducido por con indica según Cano Aguilar (1999: 1835) «el contenido de las imágenes oníricas, directas o metafóricas».

${ }^{70}$ Tanto Cano Aguilar (1981: 387) como, por ejemplo, Gutiérrez Araus (1987: 380), señalan que el complemento preposicional de soñar puede convertirse en un sintagma como lo soñado. Sin embargo, del ejemplo utilizado por Gutiérrez Araus (Ayer soñé con algo extraño: lo soñado fue...) (1987: 380) parece inferirse que lo transformado es, en realidad, el 'objeto efectuado': ayer soñé con algo extraño: lo soñado fue (*on) que estaba en una habitación rodeado de...
} 
predicados $^{71}$; aunque «refinar» el análisis semántico de los verbos hace aparecer un número de distinciones mucho más amplio que el que suele recogerse en los inventarios. Utilizando un ejemplo de Van Valin (1996), 'conocedor' y 'perceptor' no parecen adecuados como papeles semánticos, porque las diferencias entre ambos no parecen relevantes para la gramática. 'Experimentador', en cambio, es un papel semántico que abarca lo que tienen en común 'conocedor' y 'perceptor' y otros muchos papeles específicos.

Sin embargo, se podría seguir generalizando, porque no sólo, por ejemplo, las 'causas' y los 'agentes' tienen rasgos en común que permiten agruparlos; también 'experimentador' - el sujeto de odiar, admirar, ver - y 'agente' comparten rasgos semánticos y pueden codificarse de la misma manera en el plano sintáctico ${ }^{72}$.

Pero aunque la generalización, con los problemas que conlleva, sea un proceso necesario, si se quiere contar con un número limitado de papeles que recubra una amplia gama de significados, se corre también el peligro de que, en el proceso, acaben por vaciarse de significado. Así, según advierten Rappaport y Levin (1988: 17), conforme se amplia la clase de predicados es más probable que los verbos no coincidan en sus características semánticas, aunque sus argumentos se expresen de las misma manera; que papeles como 'paciente' o 'tema' acaben siendo, simplemente, el objeto directo de una construcción transitiva o el argumento al que asigna directamente papel semántico el verbo; en definitiva, puede ocurrir que se consideren 'paciente' o 'tema' los complementos de la casa presentaba un aspecto magnífico, Luis tenía una finca, trasladó las cajas, habla inglés, no tanto por aspectos semánticos como porque son el objeto directo de una construcción sintácticamente transitiva; o que se considere 'paciente' o 'tema' el complemento de habla en inglés, habla de política, discrepo de sus opiniones por suponer que, al fin y al cabo, son un 'argumento interno' al que el verbo asigna directamente papel semántico.

A la resolución del dilema que se plantea entre la necesidad de generalizar y el inventario de distinciones más amplio que parece requerir el análisis semántico de los verbos, a fin de captar contrastes y semejanzas de significado, parecen apuntar las propuestas tendentes de diferenciar varios tipos de papeles según se atienda más a la semántica del verbo o a la realización gramatical.

En esa línea cabría, por ejemplo, situar la distinción que establece Goldberg (1995) —al igual que Fillmore y Kay (1993) — en el marco de la «Construction

7 Como indica Dowty (1991: 556) al respecto, «I think es an implicit principle that we should not postulate a thematic role type that is limited to only one or two verbs (or a small set of near sinonymous) but should rather expect each role type to be applicate to a reasonable range of verbs meaning»

72 Como señala Demonte (199lb: 40): «En español y en la mayoría de las lenguas que se conocen los verbos que designan actividades cognitivas, sean estas linguísticas, proposicionales o perceptivas, se caracterizan por pertenecer sintácticamente al patrón Agente-Paciente (...) con otras palabras, son verbos transitivos». 
Grammar», entre dos tipos de papeles: los 'argumentales' y los 'participantes'. Estos se asocian al marco semántico del verbo ${ }^{73}$, en tanto que los 'argumentales' 'agente', 'paciente', 'meta', etc.- serían más generales y se asociarían a las funciones gramaticales.

Asimismo, la diferenciación que postula la «Role and Reference Grammar» entre 'relaciones temáticas específicas' - 'agente', 'experimentador', 'origen', 'instrumento', 'fuerza', 'locación', 'tema', 'paciente', 'ruta'-, abstracción, a su vez, de papeles más concretos — 'perceptor', 'conocedor' etc.- y 'relaciones temáticas generales' o 'macro-roles' - 'actor', 'undergoer'- (Van Valin y LaPolla, 1997), parece justificada por ese dilema que se plantea entre la delimitación de las distinciones necesarias para explicar contrastes y semejanzas en el significado de los verbos y la generalización que requiere la gramática.

De conformidad con Van Valin y LaPolla (1997), las relaciones temáticas específicas representarían aspectos del significado de los verbos, en cuanto que reflejarían las relaciones semánticas entre los predicados y los participantes en el estado de cosas denotados por ellos. Así, por ejemplo, 'agente', 'tema', 'locación' podrían ser relaciones temáticas específicas para verbos como spray o load (she sprayed the paint on the wall, he load the hay onto the truck).

'Actor' y 'undergoer' implican un nivel más alto de abstracción. Son papeles más generales, cuyo sentido parece difícil de concretar, pero que subsumen relaciones temáticas específicas y tienen consecuencias gramaticales significativas: agrupan, en definitiva, los argumentos que se realizan como sujeto y como objeto directo en una construcción transitiva.

'Actor' subsume -y neutraliza- relaciones como 'agente', 'fuerza', 'instrumento', 'experimentador', 'origen', «a group of arguments indicating doers of an action in some general sense» (Van Valin y LaPolla, 1997: 140). Su prototipo es el 'agente' (1997: 143), aunque «actor does not necessarily means agent, but rather some more general» (1997: 142 )

'Undergoer' agrupa - y neutraliza - 'paciente', 'tema', 'locación'; el grupo «which seems to encompass the things affected by an action» (Van Valin y LaPolla, 1997: 143). Su prototipo es el 'paciente', aunque no significan. exactamente "cosas que experimentan un cambio de condición o estado", «they are things which undergo something in a general sense» (1997: 142).

De todas maneras, lo que parece justificar la agrupación en torno a los dos macro-roles 'actor', 'ungergoer' es que «the grammar, for certain purposes, treat these roles as essentially the same», «the actor is the subject», «and the undergoer is the direct object in the English active» (Van Valin y LaPolla, 1997: 140-141).

73 Thief, target, goods serían, por ejemplo, los papeles participantes asociados a rob y steal (Goldberg, 1995: 45). 
Evidentemente, los 'macro-roles' se sitúan en un nivel de generalización más alto que los 'papeles argumentales' de que habla Goldberg; estos más bien coincidirían, a juzgar por el inventario, con las 'relaciones temáticas específicas'. Pero, a pesar de las divergencias en cuanto al nivel de generalización que se precisaría, de cara a vincular 'papeles' con 'relaciones gramaticales', interesa señalar, por un lado, el hecho mismo de que coincidan en la necesidad distinguir tipos de papeles pertinentes en diferentes niveles; por otro lado, que tanto Goldberg como Van Valin y Lapolla y también, por ejemplo Dowty, apuntan a diferencias significativas entre las relaciones semánticas establecidas mediante funciones gramaticales 'directas' y las que se establecen mediante otros esquemas.

Así, por ejemplo, si consideramos el ya tan conocido ejemplo de alternancia locativa cargó el trigo en el camión/ cargó el camión con trigo, desde el punto de vista de Van Valin y LaPolla (1997), admitiendo incluso que las 'relaciones temáticas específicas' sean las mismas en ambos construcciones, sólo se asignaría el papel de 'undergoer' —el que tiene como prototipo el papel 'paciente', el que se refiere a «things which undergoes something in a general sense» (Van Valin y LaPolla, 1997: 142) - al elemento que, en cada caso se realiza como objeto directo $^{74}$ : «A speaker can choose which argument he/she wants to focus on as being, the one being, primarily affected, and can therefore code it either way» (1997: 145). Asimismo, asumiendo el punto de vista de Dowty (1991), sólo como objeto directo el camión, el trigo, son 'proto-pacientes', en cuanto que implican 'tema incrementativo'. Para Goldberg, por último, los 'roles participantes' de cargar son también en los dos casos los mismo, pero, además de que sólo el sujeto y el objeto directo son 'perfilados' por la construcción, el camión sería «un tipo de paciente» en cargó el camión, pero no, evidentemente, en cargó el trigo en el camión (Goldberg, 1995: 177-178).

Ni los 'papeles' utilizados por Demonte $(1989,1991)$ y por Gràcia $(1989)$, ni las nociones empleadas por Cano Aguilar (1999) o por García-Miguel (1995) para referirse a los aspectos semánticos de las construcciones con complemento preposicional guardan relación directa con los 'macro-roles' o con los papeles específicos planteados por Van Valin y LaPolla o por Goldberg. Demonte, por ejemplo, utiliza un único tipo de papel semántico, sin diferenciar niveles de generalización o papeles asociados al marco semántico del verbo y papeles asociados a la construcción. En cuanto a las nociones empleadas por Cano Aguilar o García-Miguel para describir el sentido del complemento preposicional — del tipo 'asunto', 'materia', 'campo nocional', etc.- queda ya dicho que parecen situarse en un nivel más específico, más próximo a la semántica de la unidad verbal, aunque, como se ha señalado antes, no sean realmente equiparables, por ejemplo, a

74 Según su planteamiento, 'tema' y 'locación' son potenciales 'undergoer', aunque 'tema', como más próximo al 'paciente', sería la opción no marcada como 'undergoer'. 
los 'papeles participantes' de que habla Goldberg. En cambio, el concepto de 'paciente' o el concepto de 'referencia' al que alude García-Miguel sí parecen situarse - especialmente este último- en un nivel de generalización más alto.

De todas maneras, si trasladamos los postulados de Goldberg, de Dowty o de Van Valin y LaPolla a las alternancias del tipo discutir de politica/ discutir las condiciones del pacto, pensar un plan de actuación/ pensar en el tiempo pasado, se podría colegir que el análisis de García-Miguel se aproxima más que el de Demonte - Gracià al que cabe inferir de esos postulados: aunque los complementos coincidan en ambos casos en aludir a un 'tópico' o 'tema' de 'la conversación' o de 'lo pensado' y reflejen igualmente aspectos implicados por el contenido semántico de los predicados, no pueden ser equiparables en el nivel de los 'macro-roles', de los 'proto-roles' o de los 'papeles argumentales' 'perfilados' por las funciones gramaticales: sólo en la construcción transitiva podría hablarse, por ejemplo, de 'actor' y 'undergoer', de un 'tipo de paciente' o de un 'proto-paciente'. En una construcción intransitiva no cabría un esquema semántico 'actor'- 'undergoer'.

3.3. La interpretación de alternancias como las que anteriormente se han mencionado nos lleva a otro aspecto que, a mi juicio, es realmente problemático: 10 que podríamos llamar la relación de determinación entre papeles semánticos y entornos sintácticos.

No me refiero exclusivamente a cuestiones tales como la ordenación de los papeles en jerarquías vinculadas al funcionamiento sintáctico, sino sobre todo a otras cuestiones cuya respuesta parece depender, en mayor medida, de los marcos teóricos utilizados: si la determinación de los papeles tiene como base sólo el significado o también las relaciones sintácticas en que aparecen configurados (Dowty, 1991: 554); si son los papeles vinculados a la estructura argumental del verbo - la que se les asocia en el lexicón o diccionario- los que determinan la realización sintáctica de los argumentos; si se mantienen constantes aunque varíe el entorno sintáctico del verbo, o si, por el contrario, se reconoce cierta entidad autónoma a la construcción, se le supone cierto importe semántico; si las relaciones gramaticales configuran, de alguna manera, 'papeles semánticos'.

En los trabajos de Demonte $(1989,1991)$, Gràcia i Solé (1989) y García-Miguel (1995), se hallan implicadas, en realidad, dos perspectivas diferentes sobre las relaciones entre el léxico y los entornos sintácticos.

Demonte y Gràcia - como es propio del modelo generativista «Principios y Parámetros»- adoptan lo que, en términos de Goldberg (1995: 2), podríamos catalogar como una perspectiva «entirelly lexically based or bottom up» ${ }^{75}$ : la sintaxis es una proyección de las propiedades de los elementos léxicos y los papeles

75 Perspectiva a la que Goldberg atribuye una cierta circularidad. 
que, en la estructura básica, asigna el verbo a las posiciones argumentales o a los argumentos se mantienen invariables, aunque cambie la configuración sintáctica de estos. Utilizando un ejemplo quizá demasiado simplificado, se podría decir que, desde esta perspectiva, en discutieron las condiciones del pacto, las condiciones del pacto se realiza como argumento directo porque corresponde al argumento 'paciente' o 'tema', el argumento 'interno' al que asigna directamente papel semántico el verbo. El papel se mantendría en discutieron de política porque sigue correspondiendo al argumento 'interno' del verbo, aunque haya que explicar, por otras razones, por qué no se realiza como argumento directo.

Desde una perspectiva que podríamos asociar, por ejemplo, a la «Construction Grammar» o a la Gramática Cognitiva, se reconoce en la propia construcción Sujeto-V-Objeto directo o en la construcción Sujeto-V-Complemento preposicional una estructura semántica, una naturaleza simbólica ${ }^{76}$, un «importe nocional» y las construcciones no se consideran totalmente condicionadas por el verbo ${ }^{77}$, sin que ello implique que no exista relación entre clases semánticas de verbos y tipos de construcción ${ }^{78}$. Así, se podría decir, por ejemplo, que discutir, como otros verbos de «decir» - hablar, murmurar, por ejemplo-, pueden expresar de maneras distintas el 'tópico' de conversación o la 'verbalización' implicados por el significado del verbo: discutieron de política, discutieron el asunto, pero el papel de 'paciente' — con las propiedades que implica — vendría dado por la estructura Sujeto-V-Objeto directo; de ahí que no sean totalmente equivalentes, en su significado, ambos tipos de complemento.

El trabajo de García-Miguel se sitúa más en la línea de esta segunda perspectiva: admite cierta versatilidad en las unidades léxicas por lo que concierne a su capacidad combinatoria ${ }^{79}$; asume, asimismo, como anteriormente se ha indicado, el carácter significativo de la construcción, del esquema sintáctico, de las relaciones o funciones gramaticales como parte de ese esquema sintáctico: las funciones sintácticas gramaticalizadas (sujeto, objeto directo), en primer lugar, sitúan «en perspectiva», destacan como centrales, como prominentes determinados

76 Desde el punto de vista de Goldberg (1995: 5), por ejemplo, «simple clauses constructions are associated directly with semantic structures which reflects scenes basic to human experience».

77 Como advierte Goldberg (1995: 29) es preciso admitir cierta libertad, al menos para poder explicar los usos nuevos.

78 De conformidad con Goldberg (1995: 25), «Although I have argue that constructions have meaning independently of the verbs, it is clearly not the case that the grammar works entirely top-down, with constructions simply imposing their meaning on unsuspecting verbs. In point of fact, there are reasons to think that the analysis must be both top-down and bottom-up (...) the meanings of constructions and verbs interact in non trivial ways and therefore some cross-reference between verbs and argument structures will be necesary».

79 Aunque «ni el esquema sintáctico es sólo consecuencia automática de la elección del predicado, ni un esquema sintáctico clausal admite ser rellenado arbitrariamente por cualesquiera elementos léxicos» (García-Miguel, 1995: 24). 
participantes en la situación, en el estado de cosas denotado por la predicación ${ }^{80}$. Las funciones no centrales «u oblicuas» constituyen el «fondo o segundo plano» (García-Miguel, 1995b: 44).

En segundo lugar, también parece aceptar García-Miguel que, según han señalado distintas teorías de la órbita funcional, las funciones 'sujeto' y 'objeto' como integrantes de un esquema sintáctico transitivo conllevan algún tipo de simbolismo; imponen una determinada organización de la escena en la que ambas funciones asignan a los participantes centrales un diferente estatus ${ }^{81}$.

Por tanto, difícilmente podría plantear como equivalentes desde el punto de vista semántico - y eso incluye a los papeles semánticos - una construcción con complemento directo -ha cometido un delito, ha soñado que lo perseguían, discutieron el asunto, pienso que me han engañado, eligió el premio en metálico, rechazó el puesto- y una construcción con complemento preposicional - ha incurrido en un delito, ha soñado con ellos, discutían de política, pienso en ti todos los días, optó por el premio en metálico, renunció al puesto- aun cuando coincidan en el significado del verbo; ni podría admitir como equivalentes en su significado las alternancias CDIR/CPREP con el mismo verbo: «al cambiar la función sintáctica cambia también su relación semántica con el resto de la predicación» (1995: 15). No se olvide, además, que a las diferencias relacionadas con la propia construcción, habría que añadir, desde su punto de vista, las que aporta el propio significado de la preposición

3.4. Son ciertamente muchas más las cuestiones problemáticas que se han ido suscitando en el ámbito de los papeles semánticos y que, como es lógico, podrían hallarse implicadas en la interpretación de esos objetos preposicionales que se han ido destacando. Entre ellas:

1) La dificultad para definir las nociones de un modo preciso, y aún más, para aplicarlas de forma no ambigua a los elementos que se van analizando: una misma definición podría ser aplicable a elementos diferentes o, al contrario, un mismo elemento podría ser asignado a dos o más papeles semánticos diferenciados. De ahí

\footnotetext{
80 Según Goldberg, asimismo, «Every argument role linked to a direct grammatical relation (SUBJ, OBJ or OBJ2) is constructionally profilled» (1995: 48) y añade más adelante: «It is important to note that the profiling of participants roles (...) and the profiling of argument roles are not of the exact same kind (...) In the case of argument roles, all and only role which are expressed as direct grammatical relations are considered profiled» (1995: 49).

81 Que el «importe conceptual» del 'sujeto' y del 'objeto' no pueda ser definido en términos de papeles semánticos - 'agente', 'paciente'- o informativos parece algo fuera de duda. Más difícil parece ser precisar en qué consiste el valor esquemático, abstracto, que subyace tanto al esquema transitivo prototípico como a los esquemas desviados. Ni siquiera el esquema 'punto de partida/origen', 'punto de llegada/ término' en la cadena de causación parece adecuarse a los predicados de estado. Pero sí que parece claro, al menos, que el prototipo de 'paciente', como tantas veces se ha apuntado, sólo parece asociarse a la función objeto directo.
} 
que, con bastante frecuencia, se haya señalado que «en ocasiones, la interpretación del papel-theta de un SN parece depender de la intuición de cada gramático» (De Miguel, 1992: 45).

Así, los complementos de acceder (a), aspirar (a), optar (a) que, según los análisis de García-Miguel o de Cano Aguilar, tienen sentido 'direccional', señalan 'la situación a la que se desea llegar', el 'punto de referencia final', podrían encajar tanto en el concepto de 'referencia' como, por ejemplo, en el concepto de 'meta' utilizado por Gràcia i Solé (1989: 314), en el que viene a encuadrar complementos con sentido «abstracto» y con sentido espacial: «punt final que no rep les consequències de l'estat de coses (com a [anirem al Parc Güell, tendia a la perfecció]) o que les rep en segon lloc». Pero también podrían entenderse como 'pacientes', si en ese concepto se incluyen tanto 'objetos afectados o efectuados' como 'objetos no afectados ni efectuados ${ }^{, 82}$ (miró a su hermano). Al fin y al cabo, un objeto no afectado ni efectuado sólo puede entenderse como la entidad hacia la que se orienta el proceso, y los complementos preposicionales mencionados parecen ajustarse a este concepto.

2) A los problemas ya señalados y a los que resultan de las diferencias en la definición incluso de los papeles más utilizados - 'paciente', 'tema', 'agente', entre ellos-, habría que sumar los que proceden de la falta de inventarios que den cuenta, de manera exhaustiva, de los papeles que pueden ser necesarios ${ }^{83}$. Esto quizá pueda motivar que, a veces, se fuercen relativamente las interpretaciones para para poder encajar los argumentos en los papeles más consolidados.

Así, por ejemplo, se ha apuntado que ninguno de papeles más comúnmente utilizados parece ajustarse a los complementos que se subrayan en los siguientes enunciados: this is similar to that, this resembles that, hi risked death, we resisted the enemy (Starosta, 1978: 469; Dowty, 1991: 556; Fillmore y Kay, 1993).

Tal vez el problema que suscita, en general, el carácter incompleto de los inventarios se vea acrecentado si nos adentramos en el campo de los objetos preposicionales de carácter abstracto, para los que se han postulado valores tales como 'origen abstracto', 'locativo abstracto', 'dirección' o 'meta abstracta'; valores que, desde luego, no pueden equipararse a los 'locativos', 'metas', etc., con sentido

\footnotetext{
82 El que se conceptúen como 'objetos' estaría motivado, en definitiva, por su configuración como objeto directo.

83 Decía Dowty al respecto que «although many linguists seem to assume that linguistic theory should include a finite (and short) language universal canon of thematic roles (...) no one that i know of has ever attempted to propose a complete list) (1991: 548). Asimismo señalaba Atkinson (1992: 2) como un aspecto clave para una teoría que asuma una relación entre representaciones sintácticas y papeles semánticos el tratar de dar respuesta a la cuestión «what is the inventory of theta roles needed for a complete theory of lexical representations?».
} 
local estricto ${ }^{84}$ y que tampoco se identifican claramente con los papeles más comúnmente manejados.

En definitiva, parece que, según señalaba Bosque (1989:82), «no disponemos de un buen aparato conceptual para designar las funciones argumentales, de modo que los términos que habitualmente se les asigna son muy pobres en matices y no contienen las distinciones necesarias».

3) Se podrían mencionar también, por último -aunque, evidentemente, con ello el tema no queda agotado- las dificultades para trazar límites claros entre lo que corresponde estrictamente a los papeles semánticos y lo que pueda pertenecer al dominio de lo pragmático, o los problemas que conlleva la relación entre los papeles con una categoría tan compleja como el 'aspecto', categoría que en la actualidad se ha postulado (véase Grimshaw, 1990, De Miguel, 1992) como un componente estrechamente vinculado - aunque de diferentes maneras- a los papeles semánticos.

Tanto Demonte (1989; 1991), como García-Miguel (1995) apelan a distinciones aspectuales ('telicidad', 'delimitación del evento' 'atelicidad', 'no delimitación') en sus análisis sobre los objetos preposicionales. Pero quizá pueda dar una idea de la complejidad que puede entrañar el tema el hecho de que Demonte y García-Miguel ni parecen coincidir en sus planteamientos, ni coinciden en sus conclusiones ni tampoco coincidirán plenamente en las interpretaciones «aspectuales» de algunos elementos en concreto.

Para Demonte, las diferencias entre la realización directa y la preposicional (pensar/ pensar en, soñar/ soñar con, pelear/pelear por, renunciar/ renunciar a) son básicamente de naturaleza aspectual. Con el complemento directo (pensó una palabra, soñó una tormenta, renunció su puesto, peleó su puesto (1989: 94; 1991: $106,108)$ ), se expresa acción delimitada, acabada, compatible con adverbios y giros verbales que indican acción acabada (1991: 106). Con el complemento preposicional (pensó en una palabra, soñó con una tormenta, renunció a su puesto, peleó por su puesto), se expresa acción no delimitada, centrada en el proceso verbal, compatible con adverbios y giros verbales que indican proceso en realización. De ahí su conclusión: «no nos encontramos con una verdadera preposición (...) sino con una marca de una variante del Caso acusativo (un «acusativo preposicional») que surge condicionada por propiedades aspectuales del predicado verbal» (1989: 95).

También para García-Miguel entre, por ejemplo, discutir de política (proceso atélico) y discutir el asunto (proceso télico, «con un límite inherente que se alcanza cuando se agota el tema y/o se ha llegado al resultado» (1995: 145), hay una diferencia de 'aspecto'. Sin embargo, de su análisis no se deduce que el

\footnotetext{
${ }^{84}$ Aunque puedan vincularse en niveles más abstractos, como los que corresponden, por ejemplo, a los conceptos de 'fondo' y 'figura'.
} 
contraste entre CDIR y CPREP se pueda reducir a una diferencia entre 'delimitación'/'no delimitación' del evento; o que la 'no delimitación' sea una característica constante de los verbos «agentivos» que seleccionan un argumento interno que se realiza como CPREP y no como complemento directo. En tanto que propiedad de la cláusula, la 'aspectualidad' se configura como algo bastante más complejo: se halla vinculada a los grados de 'afectación' y de 'individuación' del objeto, a las características semánticas del verbo, a la existencia de satélites que delimiten o no delimiten el evento.

Así, hablar inglés, parece tan atélico como hablar en inglés, por ejemplo; con verbos como gozar, disfrutar, o creer, según García-Miguel (1995: 114-115), tanto la construcción directa como la prepositiva parecen designar situaciones durativas y sin límite inherente. Tampoco queda excluida la 'telicidad' de las construcciones intransitivas ${ }^{85}$, de las construcciones con complemento preposicional: renunció a su puesto, por ejemplo, no parece un evento 'no delimitado' que pueda extenderse indefinidamente en el tiempo. En el presidente renunció a su puesto a lo largo del año (Demonte, 1991: 108), el complemento a lo largo del año difícilmente puede entenderse como el espacio temporal durante el cual se lleva a cabo el acto de renunciar.

Por tanto, si bien García-Miguel señala el contraste entre 'delimitación' ('telicidad') y 'no delimitación' como uno de los rasgos que, asociado al mayor o menor grado de afectación de la entidad denotada por el complemento directo o el preposicional, tiende a correlacionar con los cambios de esquema sintáctico, no se infiere de su análisis que esta diferencia constituya una constante ni que, por lo demás, sea la única ni la fundamental que se puede asociar al cambio de esquema SUJ-PRED-CDIR, SUJ-PRED-CPREP.

\section{Los papeles semánticos de los objetos preposicionales: un campo problemático}

Una vez examinadas algunas de las cuestiones problemáticas que suscita el tratamiento de los papeles semánticos —cuestiones que, según se ha ido señalando, pueden estar implicadas en la diversidad que hemos observado en lo que concierne a la interpretación de determinados objetos preposicionales—quizá podría parecer que está justificado el pesimismo de algunos sobre la viabilidad de una teoría «completa» de los papeles semánticos, o el escepticismo sobre su valor explicativo en los procesos sintácticos. Y ciertamente, el panorama podría ser aún más sombrío si nos adentramos en ese campo de los papeles asociados a las estructuras con

85 Los 'logros', por ejemplo, aun cuando sean intransitivos (Van Valin y LaPolla, 1997: 92) parecen denotar eventos 'télicos'. 
complementos preposicionales de contenido «abstracto», que se alejan de los papeles vinculados al esquema transitivo o de los complementos con contenido «local», los más considerados, en definitiva, cuando se habla de papeles semánticos.

No se olvide, además, que en el caso del complemento preposicional, a los problemas que suscitan la propia noción de papel semántico, su inventario, los criterios utilizados para delimitarlos, su relación con los esquemas sintácticos y con otros aspectos semánticos y pragmáticos, habría que añadir los que rodean a otro elemento no menos problemático, sobre el que ahora no puedo extenderme por razones ya de espacio: la preposición y las no menos complejas cuestiones que rodean a su estatus ${ }^{86}$ y a su significado: si puede hablarse de preposiciones 'vacías' y si es así, cuándo ${ }^{87}$, o si hablar de preposiciones 'vacías' es sólo una consecuencia

85 Por ejemplo, en la Gramática Funcional de Dik las preposiciones no figuran entre los elementos léxicos. Como indica Sancho Cremades (1995: 47), «són les regles d'expressió les que assignen la preposició escaient per a cada funció semàntica». En el modelo «Principios y Parámetros», en cambio, las preposiciones «plenas» «actúan como asignadoras de papel temático» (Fernández Lagunilla y Anula Rebollo, 1995: 243).

87 Como ya se ha indicado con anterioridad Cano Aguilar (1999: 1818) concluía en su último trabajo sobre los complementos preposicionales de régimen verbal que no suele haber pruebas objetivas de que la preposición carezca por completo de sentido. Señalaba, además que «hechos opuestos como la posibilidad y la imposibilidad de sustituir la preposición introductora, pueden ser utilizados como criterios para una misma finalidad» (1999: 1815). Se podría añadir que algunas de las pruebas utilizadas para justificar si una preposición es «vacía» o «falsa» están bastante sujetas a variaciones de aceptabilidad. Así, por ejemplo, una de las pruebas que aduce Demonte (1991) para justificar que las preposiciones que acompañan a los verbos de la clase (2) son falsas es el hecho de que no se pueden omitir en estructuras de coordinación. Así, por ejemplo, puesto que confiar en aparece incluido en ese grupo, cabe esperar que no admita esa omisión. Sin embargo, entre los ejemplos de objeto preposicional citados por Alarcos (1994: 284) figura confio en la suerte y la intuición, una estructura coordinada en la que no se repite la preposición.

En otro plano, el hecho de que, como se indicó anteriormente, Gracià i Solé evite afirmaciones concluyentes cuando trata del significado de la preposición —predomina, en su exposición, el «puede ser», «parece como si», «la idea intuitiva es que»- en los complementos regidos parece un claro indicio de su carácter conflictivo. Así, por ejemplo, comparando El cuiner va posar l'enciam al plat, En Pere venia de Salou y El nen es va acostumar aviat a la seva presència, En Joan parlava del Congrès, señala que el sentido que tiene la preposición en los dos primeros ejemplos, «es mes dificil de trobarlo» en a la seva presencia o del Congrès. En estos «sembla com si la preposició no aportase res a la interpretació dels complements. No és fácil decidir fins a quin punt aquestes preposiciones intervenen a l'assignació del paper-theta; però d'alguna manera hi ha d'incidir, como ho demostra el fet que no siguin intercanviables i que, per tant, algun tipus de valor semàntic encara conservin. Pot ser més que intervenir directamente hauran de «respectar» el paper-theta exigit pel verb» «la idea intuitiva és que en certs casos el que té més força a l'hora de determinar el paper-theta es el verb y no la preposició. Si comparem els exemples (...) sembla que a [El nen es va acostumar aviat a la seva presència, En Joan parlava del Congrès] tingui més força el verb, mentre que a [El cuiner va posar l'enciam al plat, En Pere venia de Salou] la preposició hi té un paper més important» (1989: 57). Asimismo, si, por ejemplo, en En Joan es va oblidar dels fills de la Maria algun dato «ens podria fer pensar que de es una falsa preposicio, una marca de cas», también cabe matizar que «no es del tot clar que aixó sigui cert» (1989:64). 
de nuestra incapacidad para motivar un uso preposicional (Sancho Cremades, 1995: 118); si puede reconocerse realmente en todos los usos preposicionales un significado básico ${ }^{88}$; hasta qué punto se pueden relacionar, mediante extensiones metafóricas los usos «abstractos» y los usos locales; cómo separar la «rección semántica» y la «fijación histórica» (véase López Martínez, 1972; Luque Durán, 1974; Morera, 1988; Rauh, 1994; Rauh, 1993; Sancho Cremades, 1995; Cifuentes Honrubia, 1996); son algunas de las cuestiones que hay que tomar en consideración para analizar los papeles semánticos asociados a los complementos preposicionales, como revelan asimismo los contrastes entre los análisis de Demonte, Gracià, García-Miguel y Cano Aguilar.

Parece conveniente apuntar, en cualquier caso, que un análisis realmente significativo de los papeles que se puedan vincular al complemento preposicional debe orientarse, no en la línea de la correspondencia con los papeles más consolidados, sino en la línea del «refinamiento» de las distinciones - y, por tanto, de los inventarios-; del «refinamiento» del análisis semántico de los verbos y los papeles específicos que puedan relacionarse con ellos; de la distinción entre los que son papeles asociados a las funciones gramaticales y lo que son papeles propios del marco semántico del verbo o de clases semánticamente homogéneas de verbos.

Al fin y al cabo, como sugería la cita de Gutiérrez Ordóñez que se incluía al comienzo de este trabajo, los papeles de los complementos preposicionales, en tanto que no se corresponden con «participantes centrales», deben de estar más próximos a la diversidad de los circunstanciales que a los papeles asociados a las funciones sintácticas centrales.

\section{Referencias bibliográficas}

Alarcos Llorach, E. (1968): «Verbo transitivo, verbo intransitivo y estructura del predicado", Archivum, 18, 5-17 [Alarcos Llorach, E., Estudios de gramática funcional del español, Madrid, Gredos, 1980. $3^{\text {a }}$ ed., págs. 148-162]

Alarcos Llorach, E. (1980): «Aditamente, adverbio y cuestiones conexas», en Alarcos Llorach, E., Estudios de gramática funcional, Madrid, Gredos, $3^{a}$ ed., págs. 307-341.

Alarcos Llorach, E. (1994): Gramática de la lengua española, Madrid, EspasaCalpe.

Atkinson, M. (1992): «Introduction», en Roca, I. M. (ed.), 1-22.

\footnotetext{
88 Según indica Sancho Cremades (1995: 32), la exigencia del valor único puede conllevar la deformación de la realidad linguística, porque muchos sentidos difícilmente se dejan reconducir a una base significativa única.
} 
Baker, M. C. (1992): «Thematic conditions on syntactic structuress: evidence from locative applicatives», en Roca, I. M. (ed.), págs. 23-46.

Bosque, I. (1983): «Dos notas sobre el concepto de 'suplemento' en la gramática funcional», Dicenda, 2, págs. 147-156.

Bosque I. (1989): Las categorías gramaticales, Madrid, Síntesis.

Cano Aguilar, R. (1981): Estructuras sintácticas transitivas en el español actual, Madrid, Gredos.

Cano Aguilar, R. (1999): «Los complementos de régimen verbal», en Bosque, I. y V. Demonte (dir.), Gramática descriptiva de la Lengua Española, Madrid, Espasa Calpe, págs. 1807-1854.

Cifuentes Honrubia, J. L. (1996): Usos prepositivos en español, Murcia, Universidad de Murcia.

Cuesta Martínez, P. (1997): «El suplemento. Problemas de caracterización y tipología», BRAE, LXXVII, págs. 57-98.

De Miguel Aparicio, E. (1992): El aspecto en la sintaxis del español: perfectividad e imperfectividad, Madrid, Universidad Autónoma de Madrid.

Demonte, V. (1989): Teoría sintáctica: de las estructuras a la rección, Madrid, Síntesis.

Demonte, V. (1991): «La realización sintáctica de los argumentos: El caso de los verbos preposicionales», en Demonte, V., Detrás de la palabra. Estudios de Gramática del español, Madrid, Alianza, págs. 69-115.

Demonte, V: (1991b): «Sobre agentes, experimentantes objetos afectados. El dilema del lexicista», en Demonte, V., Detrás de la palabra. Estudios de Gramática del español, Madrid, Alianza, págs. 23-68.

Dik, S. C. (1980): Studies in Functional Grammar, London, Academic Press.

Dik, S. C. (1997): The Theory of Functional Grammar 1, Berlin, New York, Mouton de Gruyter.

Dowty, D. (1991): «Thematic proto-roles and argument selection», Language, 67,3, págs. 547-619.

Fillmore, Ch. \& Kay, P. (1993): Construction Grammar, Center for the study of Language and Information, Stanford, California [trabajo no publicado]

García-Miguel, J. M. (1995): Transitividad y complementación preposicional en español, Verba, Anexo 40, Universidade de Santiago de Compostela.

García-Miguel, J. M. (1995b): Las relaciones gramaticales entre predicado y participantes, Santiago de Compostela, Universidade de Santiago de Compostela.

Goldberg, A. E. (1995): A Construction Grammar Approach to Argument Structure, Chicago, London, University of Chicago Press.

González Calvo, J. M. (1994): «Apreciaciones sobre la función sintáctica de suplemento», LEA, XVI/2, págs. 175-191. 
González García, L. y A. Veleiro (1991): «Construcciones pronominales y suplemento (A propósito de las «construcciones reversibles»)», Verba, 18, págs. 411-429.

Gràcia i Solé, LL. (1989): La teoria temàtica, Barcelona, Universitat Autónoma de Barcelona.

Grimshaw, J. (1990): Argument Structure, Cambridge, Massachusets, MIT Press.

Gutiérrez Araus, M. L. (1987): «Sobre la transitividad preposicional en español», Verba, 14, págs. 367-381.

Gutiérrez Ordóñez, S. (1997): «¿Hablamos del suplemento?», en Gutiérrez Ordóñez, S., La oración y sus funciones, Madrid, Arco/libros, págs. 175-194.

Gutiérrez Ordóñez, S. (1997b): «Gramática funcional: visión prospectiva», en Gutiérrez Ordóñez, S., Principios de sintaxis funcional, Madrid, Arco/Libros, págs. 468-485.

Halliday, M. A. K. (1985). An Introduction to Functional Grammar, London, Edward Arnold.

Hernández Alonso, C. (1990): «En torno al suplemento», Anuario de Letras, XXVIII, págs. 5-25.

Hernández Sacristán, C: (1986): «En torno a los verbos pronominales y su doble origen», LEA, VIII, págs. 59-72.

Hernanz, M. L. y J. M. Brucart (1987): La sintaxis. I. Principios teóricos. La oración simple, Barcelona, Crítica.

Jackendoff, R. (1987): «The Status of Thematic Relations in Linguistic Theory», Linguistic Inquiry, 18,3, págs. 369-411.

Kailuweit, R. (1993): «El sintagma preposicional como elemento nuclear de la oración española. El enfoque de la gramática de valencias»Verba, 20, págs. 255-273.

López Martínez M. L. (1970): Problemas y métodos en el análisis de las preposiciones, Madrid, Gredos.

López Meirama, B. (1997): La posición del sujeto en la cláusula monoactancial en español, Santiago de Compostela, Universidade de Santiago de Compostela.

Luque Durán, J. (1974): Las preposiciones, Madrid, SGEL.

Martínez García, H. (1986): El suplemento en español, Madrid, Gredos.

Morera, M. (1988): Estructura semántica del sistema preposicional del español moderno y sus campos de uso, Puerto del Rosario, Cabildo Insular de Fuerteventura.

Morera, M. (1994): «La función sintáctica 'régimen preposicional'», LEA, XVI/2, págs. 215-228.

Pérez, R. (1989): «Consideraciones acerca de los complementos adverbiales», Verba, 16, págs. 469-479. 
Porto Dapena, J. A. (1987): «Sobre el suplemento», Thesaurus, XLII, págs. 122136.

Porto Dapena, J. A. (1992): Complementos argumentales del verbo: directo, indirecto, suplemento y agente, Madrid, Arco/Libros.

Rappaport, M. y B. Levin (1988): «What to Do with theta-Roles» en Wilkins, W. (ed.), págs. 7-36.

Rauh, G. (1993): «On the grammar of lexical and non-lexical prepositions in English» en Zelinsky-Wibbelt, C. (ed.) The Semantic of Prepositions, Berlin, New York, Mouton de Gruyter.

Rauh, G. (1994): «Prépositions et rôles: points de vue syntaxique et sémantique», Langages, págs. 45-78.

Roca, I. M. (ed.) (1992): Thematic Structure. Its Role in Grammar, Berlin, New York, Foris.

Roegiest, E. (1983): «Funciones sintagmáticas de las preposiciones españolas «a» y «de». Gramática casual y gramática relacional», $L E A, \mathrm{~V}$, págs. 29-56.

Rojo, G. (1985): «En torno a los complementos circunstanciales», en Lecciones del I y II Curso de Lingüística funcional (1983 y 1985), Oviedo, Universidad de Oviedo, págs. 181-191.

Rojo, G. (1990): «Sobre los complementos adverbiales», en Homenaje al profesor Francisco Marsá, Barcelona, Universidad de Barcelona, págs. 153-171.

Rojo, G. (1994): «Estado actual y perspectivas en los estudios gramaticales de orientación funcionalista aplicados al español», Verba, 12, págs. 7-23.

Sancho Cremades, P. (1995): La categoría preposicional, Valencia, Universitat de València.

Starosta, St. (1978): «The one per sent solution», en Abraham, W. (ed), Valence, Semantic Case and Grammatical Relations, Amsterdam, John Benjamins, págs. 459-576.

Trujillo, R. (1971): «Notas para un estudio de las preposiciones españolas», Thesaurus, XXVI, págs. 234-279.

Van Valin, R. D. (1996): «Functional Relaions», en Brown, K. y J. Miller (eds.) Concise Encyclopaedia of Syntactic Theories, Oxford, Perfamon, págs. 98-110.

Van Valin, R. D. y R. LaPolla (1997): Syntax. Structure, meaning and function, Cambridge, Cambridge University Press.

Van Valin, R: D. y D. P. Wilkins (1999): «The Case for 'Effector': Case roles, Agents and Agency Revisited», en Shibatani, M. y S. A. Thompson, Grammatical Construcions. Their Form and Meaning, Oxford, University Press, páags. 289-322.

Vera Luján, A. (1994): Fundamentos de análisis sintáctico, Murcia, Universidad de Murcia. 
Wilkins, W. (ed.) (1988): Syntax and Semantics. Thematic Relations, Academic Press, Nueva York. 